Combustion and Flame 159 (2012) 2954-2966,

H. Yamashita, J. Kasahara, Y. Sugiyama, A. Matsuo

\title{
Visualization Study of Ignition Modes Behind Bifurcated-Reflected Shock Waves
}

\author{
Hiroki Yamashita ${ }^{*}$, Jiro Kasahara ${ }^{\dagger}$ \\ University of Tsukuba, Ibaraki 305-8573, Japan \\ and \\ Yuta Sugiyama^, Akiko Matsuo ${ }^{\text {* }}$ \\ Keio University, Kanagawa 223-8522, Japan
}

Submitted to the Combustion and Flame, Oct. $13^{\text {th }}, 2011$

\begin{abstract}
Keywords: bifurcated shock wave; ignition; reflected shock wave; boundary layer; induction time; optical visualization; shock tube
\end{abstract}

\begin{abstract}
This study was a numerical and experimental investigation of lowtemperature auto-ignitions behind reflected shock waves in which a shock tube was employed as the experimental system. We used a high-speed video camera and the Schlieren method to visualize the ignition phenomena. Experiments were performed over a temperature range from $549 \pm 10$ to $1349 \pm 11 \mathrm{~K}$ and a pressure range from $56 \pm 2$ to $203 \pm 13 \mathrm{kPa}$, and a non-diluted stoichiometric acetylene-oxygen mixture was chosen as the combustible gas. We introduced a numerical simulation to help us understand the disturbed temperature distribution behind bifurcated shock waves due to interference between reflected shock waves and the boundary layer developed behind incident shock waves. Additionally, we experimentally observed and evaluated quantitatively a tendency for ignition positions to be located farther from the reflecting wall as the temperature decreased behind reflected shock waves. To focus our attention on the ignition positions, we classified the ignition types behind reflected shock waves as near-wall ignition and far-wall ignition by $4.7 \mathrm{~mm}$ distance from
\end{abstract}


Combustion and Flame 159 (2012) 2954-2966,

H. Yamashita, J. Kasahara, Y. Sugiyama, A. Matsuo

reflecting wall. The criterion for these ignition types was estimated to be $-1.0 \leq\left(\partial t_{\mathrm{i}} / \partial T_{5 \mathrm{t}}\right)_{p_{\mathrm{t}}} \leq-0.5$. As a main object in this manuscript, we proposed an ignition model in which local ignition is induced at some distance from reflecting wall based on the numerical simulation and results; the local ignitions at a point distant from the reflecting wall are induced by the temperature rise, with the distance from the reflecting wall, immediately behind concave reflected shock waves due to developing of bifurcated shock waves. We confirmed that there is no discrepancy between the proposed model and experimental results.

${ }^{*}$ Graduate Student, Department of Engineering Mechanics and Energy

${ }^{\dagger}$ Associate Professor, Department of Engineering Mechanics and Energy

${ }^{\wedge}$ Graduate Student, Department of Mechanical Engineering

* Professor, Department of Mechanical Engineering

\section{Nomenclature}

$p_{1} \quad=$ initial fill pressure

$T_{1} \quad=$ initial temperature

$\mathrm{M}_{\mathrm{si}} \quad=$ Mach number of incident shock waves

$p_{2 \mathrm{e}} \quad=$ experimental pressure behind incident shock waves measured by pressure sensor

$p_{5 \mathrm{e}} \quad=$ experimental pressure behind reflected shock waves measured by pressure sensor

$p_{5 \mathrm{t}} \quad=$ theoretical pressure behind reflected shock waves calculated by Rankine-Hugoniot equations

$T_{5 \mathrm{t}} \quad=$ theoretical temperature behind reflected shock waves calculated by Rankine-Hugoniot equations

$T_{5 \mathrm{t}} \quad=$ simulated temperature behind reflected shock waves 
Combustion and Flame 159 (2012) 2954-2966,

H. Yamashita, J. Kasahara, Y. Sugiyama, A. Matsuo

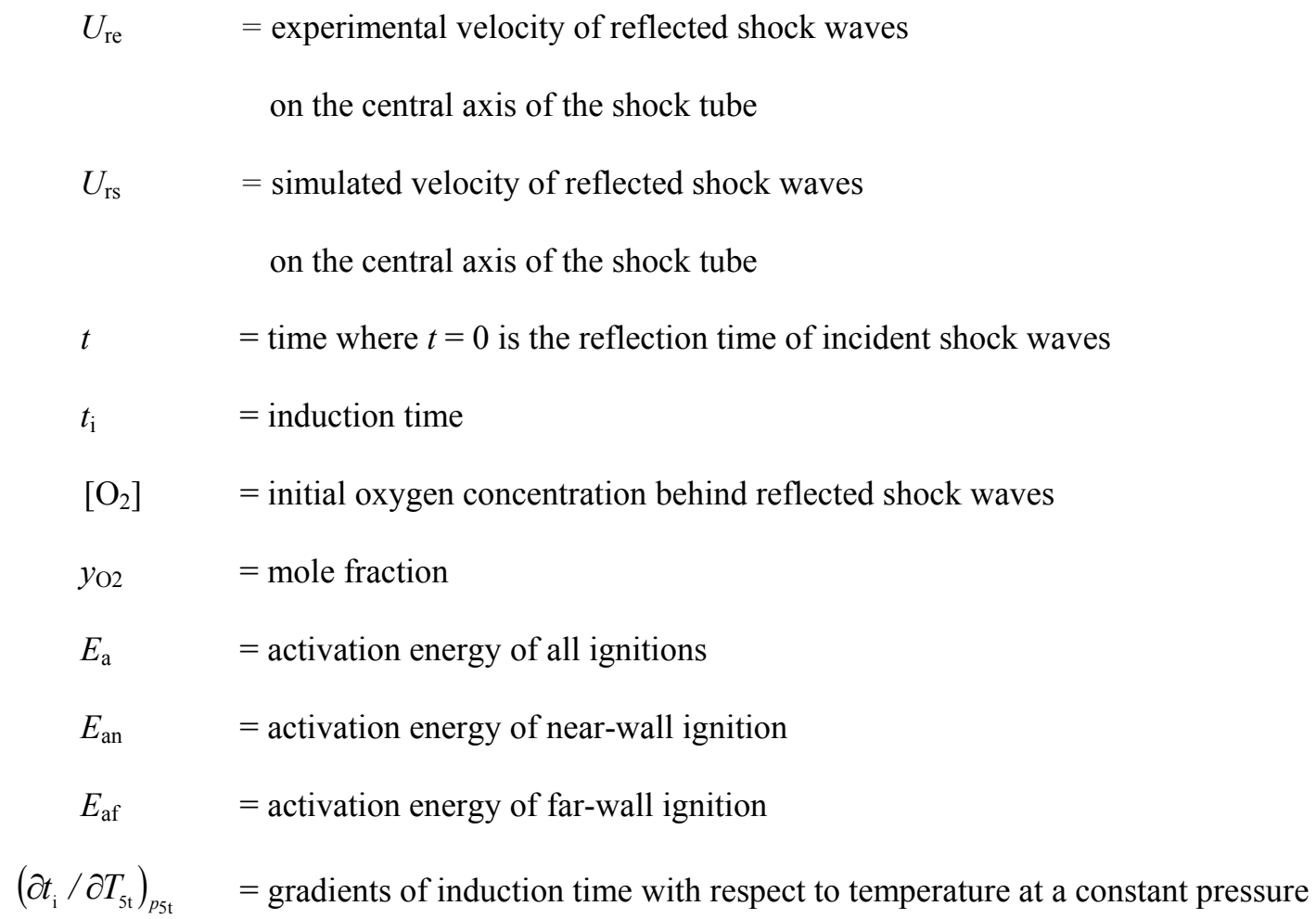

\section{Introduction}

\subsection{One-dimensional ignition behind reflected shock waves}

In a shock tube, reflected shock waves produce uniform high-temperature, high-pressure gases if conditions are ideal. Therefore, the authors of many previous studies that included theoretical discussion of ignition types behind reflected shock waves assumed that the gases behind reflected shock waves were produced under uniform conditions [1-8]. In addition, many comparisons between numerical calculations and shock tube experiments were conducted under the assumption of uniformity behind the reflected shock waves [9-11]. However, it is known that reflected shock waves interfere with boundary layers developed behind incident shock waves and transition to bifurcated shock waves and the uniformity behind reflected shock waves collapses, especially when test time is long [12-16]. 
Combustion and Flame 159 (2012) 2954-2966,

H. Yamashita, J. Kasahara, Y. Sugiyama, A. Matsuo

\subsection{Non-one-dimensional ignitions behind reflected shock waves}

Voevodsky and Soloukhin [17] observed two ignition types (sharp ignition and mild ignition) behind reflected shock waves in a hydrogen-oxygen mixture using Schlieren streak-photographs and pressure transducers. They revealed that the criterion of two ignition types was located around the second explosion limit in a hydrogen-oxygen mixture. Gilbert and Strehlow [2] theoretically analyzed the detonation transition from plane ignition behind reflected shock waves as a one-dimensional phenomenon. They also observed that a combustible mixture ignited at a local hot spot and transited to detonation waves. They reported that this ignition type tended to occor at relatively high pressure and low temperature. Meyer and Oppenheim $[18,19]$ experimentally analyzed the ignition phenomena behind reflected shock waves in a hydrogen-oxygen mixture using a stroboscopic laser-Schlieren method on the basis of results reported by Voevodsky and Soloukhin [17]. They mainly discussed ignition types near the reflecting wall and classified these ignition types as strong ignition and mild ignition. By their definition, strong ignition was plane ignition that covered a cross-section of a shock tube instantly, while mild ignition started in the form of distinct flame kernels whose growth was relatively slow. They proposed a criterion of these ignition types using induction time and temperature $\left(\left(\partial t_{\mathrm{i}} / \partial T_{\mathrm{st}}\right)=-2.0 \mu \mathrm{s} / \mathrm{K}\right)$. Takano [20] and Nikiforakis and Clarke [21] conducted several numerical simulations to compare the experimental results reported by Gilbert and Strehlow [2] and Mayer and Oppenheim [18]. Takano [20] numerically simulated ignition types behind reflected shock waves in a shock tube. He reproduced the characteristics of strong ignition starting as a planar ignition and mild ignition starting in a form of distinct flame kernels. However, there were some discrepancies; a more wrinkled reaction front was observed in the experiment, and the bifurcated limbs of the reflected shock waves in the simulation were much longer than in the experiment. Therefore, Takano's findings did not explain the ignition phenomena.

\subsection{Objective of the present study}


Combustion and Flame 159 (2012) 2954-2966,

H. Yamashita, J. Kasahara, Y. Sugiyama, A. Matsuo

The local ignitions as typified by mild ignition defined by Mayer and Oppenheim [18] are induced by the non-uniformity behind reflected shock waves. Generally the non-uniformity becomes stronger as the temperature is lower, because reflected shock waves intensively interfere with boundary layers during long induction times. Although there are many studies about the interference between reflected shock waves and boundary layers, most of these studies have been conducted on inert gases. Few studies have directly investigated the influence of the interference between reflected shock waves and boundary layers on local ignitions. In particular, little information about local ignition position has been reported. For example, Mayer and Oppenheim [18] reported only that "the reaction starts at some distinct center, usually in the stagnant region at the corners" and, recently, Heufer et al. [22] observed local ignition at a point distant from the reflecting wall, but they did not describe the ignition mechanism. However, it is important to investigate the local ignitions behind shock waves under low temperature conditions, from the point of view of chemical kinetics in high-prssure (non-diluted test gases) shock tube experiments in which the non-uniformity of reflected shock waves tends to be greater because of increased viscous effects $[23,24]$ and from the view of application systems (for example, pulse detonation engines (PDEs) [25-35] etc.). Therefore we focused on local ignitions induced by non-uniformity behind reflected shock waves under low-temperature conditions (Voevodsky and Soloukhin [17] : mild ignition, Gilbert and Strehlow [2] : hot spot initiation, Mayer and Oppenheim [18] : mild ignition) and investigated numerically and experimentally the local ignition position and the reason why local ignitions are located at a point distant from the reflecting wall.

\section{Experimental details}

Figure 1 shows an overall view of the experimental system. We employed a shock tube that consisted of a 1.4-m high-pressure section and a 2.3-m low-pressure section. These sections were divided by a 25$\mu \mathrm{m}$ diaphragm when the tube was filled with gases. An actuator that drives a needle was employed to break the diaphragm, and the shock waves started when the needle broke the diaphragm. The crosssection of the shock tube was a $50 \times 50 \mathrm{~mm}$ square. First, we conducted a calibration experiment of the 
Combustion and Flame 159 (2012) 2954-2966,

H. Yamashita, J. Kasahara, Y. Sugiyama, A. Matsuo

shock tube using helium gas and dry air as a driver gas and a driven gas, respectively. Next, to investigate the ignition phenomena behind reflected shock waves, we replaced the dry air with a stoichometric acetylen-oxygen mixture as a combustible gas. A reflecting wall was set in the vicinity of the end of the low-pressure section. Figure 2 shows a schematic illustration of the observation section. The side wall in this section was replaced by a glass window so we could visualize the phenomena. As shown in Fig. 2, four pressure sensors （PCB Piezotronics, Inc. HM113A26, 113B26） were mounted in the observation section to measure pressure histories and the velocity of incident shock waves for the calibration experiment. The distance between the nearest pressure sensor and the reflecting wall was $2.75 \mathrm{~mm}$, and the other pressure sensors were placed $35 \mathrm{~mm}$ apart from one another. As shown in Fig. 1 , we set the pressure rise induced by the incident shock as the trigger signal of the high-speed video camera, using a pressure sensor. This pressure signal was amplified through the signal conditioner and sent through the oscilloscope and delay generator to the Hyper Vision HPV-1 high-speed video camera (Shimadzu Co., Ltd.). In this study, the inter-frame time and the exposure rate of the high-speed video camera were set to $2-16 \mu$ s and $1 / 8$, respectively (the exposure rate was set to $1 / 4$ only when the interframe time was set to $2 \mu \mathrm{s}$ ). The image resolution was 312 (horizontal) $\times 260$ (vertical) pixels. We set up the horizontal axis of the shock tube to cross the optical axis of the Schlieren system. To analyze the visualization results, we defined the $x-y$ coordinate system as shown in Fig. 2 (2). The experimental conditions for shock tube calibration are shown in Table 1. The experimental conditions for visualization study of auto-ignition are shown in Table 2 (Ignition position $x_{\mathrm{ig}} \leq 4.7 \mathrm{~mm}$ ), Table 3 (Ignition position $x_{\mathrm{ig}}>4.7 \mathrm{~mm}$ ) and Table 4 (non-ignition in test time).

\section{Results and discussion}

\subsection{Calibration results of the shock tube}

To confirm the successful shock tube operation, we conducted a calibration experiment of the shock tube using inert gases. Table 1 shows the experimental conditions and results of shock tube calibration. This experiment was performed over the initial fill pressure, $p_{1}$, range from $2.0 \pm 0.1$ to $10 \pm 0.1 \mathrm{kPa}$ and 
Combustion and Flame 159 (2012) 2954-2966,

H. Yamashita, J. Kasahara, Y. Sugiyama, A. Matsuo

the incident shock waves Mach number, $\mathrm{M}_{\mathrm{si}}$, range from $1.65 \pm 0.02$ to $3.73 \pm 0.02$, and helium gas and dry air were chosen as the driver gas and driven gas, respectively. We chose dry air as a driven gas because the characteristics of dry air are relatively similar to those of an acetylene-oxygen mixture, which was chosen as a combustible gas in this study. Figure 3 shows a pressure history under the initial pressure $p_{1}=6.0 \pm 0.1 \mathrm{kPa}$ and incident shock Mach number $\mathrm{M}_{\mathrm{si}}=2.65 \pm 0.02$. In Fig. 3, the first sharp step is the pressure rise induced by incident shock waves, and the second step is the pressure rise induced by reflected shock waves. Compared to the first pressure rise, the second pressure rise became smoother with increased distance from the reflecting wall. We believe the main reason for this difference is the effect caused by bifurcation of reflected shock waves, since such waves interfere with the boundary layer developed behind the incident shock waves. In general this interference of reflected shock waves with a boundary layer does not occur in monatomic molecule gases dominantly (argon, krypton, etc.), but it turns up dominantly in a diatomic molecule gas such as dry air. Center [14] also reported that bifurcation caused the rise in pressure and temperature induced by reflected shock waves in air gas to degenerate, while bifurcation effects were not observed in pure argon gases. In other words, this pressure history shows that reflected shock waves become non-ideal shock waves as reflected shock waves propagated from a reflecting wall. For analysis, we defined each pressure value as shown in Fig. 3 , that is, the initial fill pressure is $p_{1}$ in the low pressure section, the time-averaged pressure during 100 $\mu$ from immediately after the pressure rise induced by the incident shock wave at $x=37.75 \mathrm{~mm}$ is $p_{2 \mathrm{e}}$ and the time-averaged pressure during $500 \mu$ s from immediately after the pressure rise induced by reflected shock at $x=2.75 \mathrm{~mm}$ is $p_{5 \mathrm{e}}$. Figure 4 compares the pressure ratio $p_{2 \mathrm{e}} / p_{1}, p_{5 \mathrm{e}} / p_{1}$ induced by incident shock waves and reflected shock waves in the calibration experiment to the theoretical values $p_{2 \mathrm{t}} / p_{1}, p_{5 \mathrm{t}} / p_{1}$. The dashed lines in Fig. 4 indicate the theoretical values calculated by Rankine-Hugoniot equations with assumptions based on a perfect gas. Error bars were omitted in Fig. 4, since the error size was smaller than the plot size. The experimental pressure values behind reflected shock waves are a little higher than the theoretical values, but as a whole, the experimental values had good agreement with the theoretical values around the reflecting wall $(x=2.75 \mathrm{~mm})$, which confirmed the successful 
Combustion and Flame 159 (2012) 2954-2966,

H. Yamashita, J. Kasahara, Y. Sugiyama, A. Matsuo

shock tube operation. In the following sections, we used Rankine-Hugoniot equations with assumptions based on a perfect gas to calculate the pressure and temperature values behind reflected shock waves.

\subsection{Numerical investigations of the temperature distribution behind reflected shock waves}

In order to discuss the mechanism of local ignition, at some distance from reflecting wall, behind reflect shock waves, we conducted numerical simulation. The governing equations were the twodimensional Navier-Stokes equations with 3 species $\left(\mathrm{C}_{2} \mathrm{H}_{2}, \mathrm{O}_{2}\right.$ and $\left.\mathrm{He}\right)$. The fluid was modeled on a thermally perfect gas and a frozen flow. As discretization methods, Yee's Non-MUSCL Type 2ndOrder Upwind TVD Scheme [36] and 2nd order central differential method were used for the convective and viscous terms, respectively. For the time integration, Euler explicit method was employed. The grid was orthogonal system and $\Delta x=\Delta y=25 \mu \mathrm{m}$ in all region. Computations were conducted in the twodimensional region with half-height $(0 \leq y \leq 25 \mathrm{~mm})$ and at a 100 - $\mathrm{mm}$ length from the reflecting wall ( 0 $\leq x \leq 100 \mathrm{~mm}$ ) assuming the symmetry of experimental condition at $y=25 \mathrm{~mm}$. Following conditions were imposed on boundary conditions: the gas velocities $u=v=0$ at $x=0$, isothermal wall $(300 \mathrm{~K})$ and symmetric condition at $y=25 \mathrm{~mm}$. Initial condition of incident shock waves is the same as that of shot number 54 in which we observed local ignition at some distance from reflecting wall. $\left(\mathrm{M}_{\mathrm{si}}=2.56\right.$, $\left.p_{5 \mathrm{t}}=67 \pm 5 \mathrm{kPa}, T_{5 \mathrm{t}}=953 \pm 16 \mathrm{~K}, x_{\mathrm{ig}}=28.9 \pm 0.3 \mathrm{~mm}\right)$. Figure 5 shows the temperature and vorticity distribution around the reflecting wall. Here the contour colors of temperature in Fig. 5 (b) are concentrated from $800 \mathrm{~K}$ to $900 \mathrm{~K}$ to focus on the hot spot. In what follows, the symbol $t$ written in each figure is the time where the reflection time of incident shock is $t=0 \mu \mathrm{s}$. In Fig. 5 (a), we can see that the planar parts of the reflected shock waves transition to concave reflected shock waves as pulled by the leading shock with distance from the reflecting wall. In Fig. 5 (b) from $t=40.8 \mu$ s to $t=146.5 \mu \mathrm{s}$, we observed high temperature region right behind triple point of reflected shock waves and, at $t=159.7 \mu \mathrm{s}$, we observed high temperature region right behind center of reflected shock waves. We can estimate that those high temperature regions were caused by the acceleration of concave reflected shock waves due to the growth of the leading shock waves. At $t=159.7 \mu$ s and $t=181.3 \mu \mathrm{s}$ in Fig. 5 (b), compressive waves 
Combustion and Flame 159 (2012) 2954-2966,

H. Yamashita, J. Kasahara, Y. Sugiyama, A. Matsuo

were observed. These compressive waves were induced by the extrusion of a vortex caused by flowback at $t=159.7 \mu$ s in Fig. 5 (c). Kaneko, Men'shov and Nakamura [37] also observed flowback in their numerical simulation. After $t=181.3 \mu \mathrm{s}$, compressive waves showed stronger non-uniformity behind reflected shock waves. We focused on the temperature right behind the reflected shock waves. In Fig. 6 , we compared the time variation of temperature right behind the triple point and the center of reflected shock waves, since we can guess from simulation results that both regions have higher temperature as compared to other regions. Here horizontal axis, $t$, is the time where the reflection time of incident shock is $t=0 \mu$ s and vertical axis, $T_{5 \mathrm{~s}}$, and $U_{\mathrm{rs}}$, are simulated temperature behind reflected shock waves and simulated velocity of reflected shock at $y=25 \mathrm{~mm}$. The solid line and dashed lines corresponds to the place right behind the triple point and the center of the reflected shock waves respectively. Here we can see that temperature right behind reflected shock waves increased as the velocity of reflected shock waves increased comparing $T_{5 \mathrm{~s}}$ and $U_{\mathrm{rs}}$ at $y=25 \mathrm{~mm}$. Until about $t=140 \mu \mathrm{s}$, the temperature right behind the triple point is a little higher than that behind the center of the reflected shock waves, but after $t=140$ $\mu$ s the temperature behind the center of the reflected shock waves is higher than that behind the triple point. As a whole, the temperature in both regions increased as the time passed (with distance from the reflecting wall). Therefore we can predict that the velocity variation of reflected shock waves due to transition from plane reflected shock waves to bifurcated (concave) shock waves is main factor of temperature rise. Figure 7 shows a comparison of the $t_{\mathrm{i}}-t$ on the reflecting wall and $t_{\mathrm{i}}$ right behind triple point and center of reflected shock waves. Here the linear dashed line shows $t_{\mathrm{i}}-t$ on the reflecting wall. The solid line and other dashed line show $t_{\mathrm{i}}$ with assumed the temperature right behind the triple point and the center of the reflected shock waves. Here $t_{\mathrm{i}}$, was estimated from experimental equation (5). Equation (5) will be introduced in section 3.7. The shaded regions, where the $t_{\mathrm{i}}$ assumed temperature right behind the triple point of the reflected shock waves is shorter than $t_{\mathrm{i}}-t$ on the reflecting wall, shows that local ignitions at some distance from the reflecting wall may occur because of shortening of the induction time by the temperature rise with time (with distance from the reflecting wall) as shown in Fig. 6. 
Combustion and Flame 159 (2012) 2954-2966,

H. Yamashita, J. Kasahara, Y. Sugiyama, A. Matsuo

\subsection{Proposed model of local ignitions induced by bifurcated shock waves}

In this section, we will propose a model that describes the reason why local ignition positions were at some distance from the reflecting wall under low temperature condition as reported by Heufer et al. [22]. We illustrated the temperature distribution behind developing bifurcated shock waves in Fig. 8 based on the numerical simulation results (Fig. 5, 6 and 7). We propose that traveling of the ignition position is mainly induced by temperature rise right behind concave reflected shock waves due to velocity variation with distance from reflecting wall as shown in Fig. 6. To go into more depth, the temperature rise is caused by the acceleration of the concave reflected shock waves due to interference with boundary layers. The acceleration is promoted with distance from the reflecting wall due to the growth of leading shock waves. Therefore, the temperature rise right behind concave reflected shock waves is also promoted with distance from the reflecting wall, as shown in Fig. 6. As a result, the induction time of combustible mixture at some distance from the reflecting wall is shorten dramatically by the temperature rise as the shaded regions in Fig. 7, and local ignition occurs at a point distant from the reflecting wall as shown in Fig. 8. Additionally, from the numerical simulation results in Fig. 5 (b), we can estimate that the influence of the temperature rise is pronounced mostly around the triple point and the center of reflected shock waves. In summary, we propose the possibility that the local ignition at some distance from reflecting wall is induced by developing of bifurcated shock waves because of temperature rise right behind concave reflected shock waves with distance from the reflecting wall, and local ignition tend to occur around triple point and center of reflected shock waves (Fig.8). In the following sections, we will confirm the validity of the proposed model compared to experimental results.

\subsection{Visualization results of auto-ignitions behind reflected shock waves}

The Schlieren results of the typical auto-ignitions and detonation transitions in the present study are shown in from Figs. 9-13. All experiments were conducted behind reflected shock waves and, as in Figs. 5-7, the symbol $t$ written in each figure is the time where the reflection time of incident shock is $t=0 \mu$ s. The experimental conditions are shown in from Table $2-4$, and we confirmed the detonation 
Combustion and Flame 159 (2012) 2954-2966,

H. Yamashita, J. Kasahara, Y. Sugiyama, A. Matsuo

formation under all conditions when auto-ignitions were observed. Figure 9 shows the Schlieren results of typical ignition types under the highest temperature condition $\left(1043 \pm 14 \leq T_{5 \mathrm{t}} \leq 1349 \pm 11,75 \pm 2 \leq\right.$ $p_{5 \mathrm{t}} \leq 148 \pm 10$, where the temperature and pressure range show the conditions in which a qualitatively similar ignition type was observed to those shown in Figs. 9-13). We observed that a large ignition region emerged on the reflecting wall at $t=16 \mu$ s, and this planar ignition front instantly transitioned to detonation waves. This characteristic coincided with that of strong ignition reported by Mayer and Oppenheim [18]. Figure 10 shows the Schlieren results of local ignition a near reflecting wall (1019 \pm $\left.10 \leq T_{5 \mathrm{t}} \leq 1101 \pm 11,123 \pm 3 \leq p_{5 \mathrm{t}} \leq 203 \pm 13\right)$. This ignition type tended to occur around corners formed by a reflecting wall and top or bottom surface and this characteristic coincided with that of mild ignition reported by Mayer and Oppenheim [18]. In the picture at $t=105 \mu \mathrm{s}$, we observed ignitions on the reflecting wall. We can infer from this observation that the induction time of mixture around the corner was shortened a little by the non-uniformity of temperature. In the ignition types shown in Figure 11, local ignitions start at some distance from the reflecting wall at $t=150 \mu \mathrm{s}$. From $t=154$ to $t=158 \mu \mathrm{s}$, we observed many local ignition near the reflecting wall. It is interesting that the combustion waves closely resembled bifurcated shock waves in configuration at $t=158 \mu$ s. Similar ignition types tend to occur under relatively low-temperature, low-pressure conditions $\left(956 \pm 13 \leq T_{5 \mathrm{t}} \leq 1068 \pm 13,56 \pm 2 \leq p_{5 \mathrm{t}} \leq 83 \pm\right.$ 7). In the ignition types shown in Figure 12, local ignitions occur at some distance from reflecting wall. These combustion waves transitioned to detonation waves by interference with other combustion waves. These ignition types tend to occur under higher pressure conditions $\left(927 \pm 7 \leq T_{5 \mathrm{t}} \leq 1066 \pm 13,89 \pm 3 \leq\right.$ $p_{5 \mathrm{t}} \leq 140 \pm 3$ ), as compared with the ignition types shown in Fig. 11. This characteristic is similar to that of hot spot initiation reported by Gilbert and Strehlow [2]. Similarly, in the ignition types shown in Fig. 13, local ignitions occur at some distance from the reflecting wall. However, the number of local ignition point is far less than ignition types in Fig. 12. These ignition types were observed under the lowest temperature condition ( $\left.838 \pm 62 \leq T_{5 \mathrm{t}} \leq 961 \pm 6,67 \pm 5 \leq p_{5 \mathrm{t}} \leq 130 \pm 23\right)$. These Schlieren results 
Combustion and Flame 159 (2012) 2954-2966,

H. Yamashita, J. Kasahara, Y. Sugiyama, A. Matsuo

are similar to the ignition types observed by Heufer et al. [22]. What we can see from these Schlieren results is that ignition types behind reflected shock waves are continuous phenomena. As a result, it is difficult to clearly define ignition types based on the characteristics of these phenomena.

\subsection{Relation between ignition position and temperature}

In this section, we will discuss the relation between the ignition position and temperature behind reflected shock waves. First we will define the ignition position, $x_{\mathrm{ig}}$, in the present study. Figure 14 (a) and (b) correspond to the first frame where ignitions were observed. The ignition position is defined as a center of the ignition area. In case when more than one local ignition was observed, as shown in Fig. 14 (b), the ignition position is defined as the average distance from the reflecting wall. Consequently, the ignition position $x_{\mathrm{ig}}$ is defined as follows:

$$
x_{\mathrm{ig}}=\frac{\sum_{\mathrm{j}=1}^{\mathrm{n}} x_{\mathrm{igj}}}{\mathrm{n}} \cdot \cdot(1)
$$

Figure 15 shows the relation between ignition position $x_{\text {ig }}$ and the temperature behind reflected shock waves, $T_{5 \mathrm{t}}$. We observed a tendency for the ignition position to be located farther from the reflecting wall as the temperature decreased. The ignition position was up to $37 \mathrm{~mm}$ from the reflecting wall. This result implies that the high-temperature regions shortening the induction time of combustible gases dramatically exist at a distant point from the reflecting wall as shown in Fig. 8. As a relation between ignition position $x_{\mathrm{ig}}$ and temperature $T_{5 \mathrm{t}}$, we obtained following equation (2) in a least square fit procedure:

$$
\begin{aligned}
& x_{\mathrm{ig}}=1220.9 \times T_{5 \mathrm{t}}^{-0.717} \cdots(2) \\
& x_{\mathrm{ig}}:[\mathrm{mm}], T_{5 \mathrm{t}}:[\mathrm{K}]
\end{aligned}
$$

Heufer et al. [22] reported that local ignitions occur at a point distant from the reflecting wall under low-temperature conditions. However, no previous studies have revealed the relation between ignition position $x_{\mathrm{ig}}$ and temperature $T_{5 \mathrm{t}}$ quantitatively as shown in Fig. 15 or equation (2). These results imply 
Combustion and Flame 159 (2012) 2954-2966,

H. Yamashita, J. Kasahara, Y. Sugiyama, A. Matsuo

that ignition types behind reflected shock waves are continuous phenomena, while ignition types were classified as only strong ignition and mild ignition as defined by Mayer and Oppenheim [18] until now. To focus our attention on the ignition positions, we classified ignition types as near-wall ignition $\left(x_{\mathrm{ig}} \leq 4.7\right)$ and far-wall ignition $\left(x_{\mathrm{ig}}>4.7\right)$ by the separating line at $x=4.7 \mathrm{~mm}$ from the reflecting wall. In the consideration of definition in Fig. 14 and the propagation distance within the frame time of the high-speed camera, we determined the location of the introduced separating line at $x=4.7 \mathrm{~mm}$. The maximum propagation distance within the frame time of the high-speed camera $(\leq 4 \mu \mathrm{s})$ was $9.4 \mathrm{~mm}$ assuming the instant formation of detonation waves behind reflected shock waves. In consideration of definition in Fig. 14 (a), the ignition position was $x_{\mathrm{ig}}=4.7 \mathrm{~mm}$ in this case. The velocity of the detonation waves was calculated by AISTJAN [38] (the conditions behind the reflected shock waves were $T_{5}=1000 \mathrm{~K}, p_{5}=100 \mathrm{kPa}, D_{\mathrm{CJ}}=2338 \mathrm{~m} / \mathrm{s}$ ). In summary, we can at the least say that ignition position is not located on the reflecting wall if the condition of far-wall ignition is satisfied.

\subsection{Distribution of local ignition positions behind reflected shock waves}

In the case of long-induction time, we observed bifurcated shock waves developing as a result of by interference of reflected shock waves and a boundary layer (Fig. 5, 10, 11, 12 and 13). Figure 16 shows a comparison of angle $\beta$ between Mark's theory [12] and the experimental value of the present study.

The symbol $\beta$ indicates the angle between the leading bifurcated shock waves and the top and bottom walls, as shown in Fig. 8. We can confirm that the numerical simulation did not conflict with our experiment as with regard to angle $\beta$. The experimental angle $\beta$ has a tendency to be a little larger than the Mark's theoretical values [12], but as a whole, the experimental values and Mark's theory both show the angle $\beta$ as almost constant in the experimental condition $\left(2.36 \leq \mathrm{M}_{\mathrm{si}} \leq 3.11\right)$ in which we observed auto-ignitions. Figure 17 shows the distribution of the local ignition positions of far-wall ignition with triple point trajectory of reflected shock waves. The triple point trajectory was scanned from Schlieren results of shot 54. In consideration of the results shown in Fig. 16, it is valid to compare the triple point trajectory in shot 54 and the ignition position in other shots. To put reality into 
Combustion and Flame 159 (2012) 2954-2966,

H. Yamashita, J. Kasahara, Y. Sugiyama, A. Matsuo

perspective (in the $x$ - and $y$-directions), we plotted all ignition positions in the frame in which we observed the first ignition point in far-wall ignition. As a whole, we observed a tendency for ignition points to be located around the triple point trajectory and the central axis of the shock tube. This tendency does not conflict with the model proposed in section 3.3 (Fig. 8).

\subsection{Activation energy of near-wall ignition and far-wall ignition}

First we will define the induction time, $t_{\mathrm{i}}$, in the present study. Figure 18 shows an $x$ - $t$ diagram for shot56. Here, the induction time, $t_{\mathrm{i}}$, was defined as the time difference between when we observed the first ignition and when the reflected shock waves passed the ignition position $x_{\mathrm{ig}}$. The time difference between the dashed line corresponding to $t_{\mathrm{i}}=320 \mu \mathrm{s}$ is the induction time, $t_{\mathrm{i}}$, in Fig. 18.

Figure 19 shows the Arrhenius plot. The horizontal axis is the inverse number of the temperature behind the reflected shock waves, $T_{55}$, multiplied by 1000 . The vertical axis is the induction time, $t_{\mathrm{i}}$, multiplied by the initial oxygen concentration behind the reflected shock waves $\left[\mathrm{O}_{2}\right]$. On the Arrhenius plot, the steepness of the line corresponds to the activation energy. In all shots of this study $\left(838 \pm 62 \leq T_{5 \mathrm{t}} \leq\right.$ $1349 \pm 11 \mathrm{~K}$ ), the activation energy was $E_{\mathrm{a}}=72 \pm 9 \mathrm{~kJ} / \mathrm{mol}$, and the activation energy of near-wall ignitions and far-wall ignitions was constant in experimental error, $E_{\mathrm{an}}=76 \pm 5 \mathrm{~kJ} / \mathrm{mol}$ and $E_{\mathrm{af}}=71 \pm 13$ $\mathrm{kJ} / \mathrm{mol}$, respectively. Edwards, Thomas and Williams [39] reported $71 \pm 3.5 \mathrm{~kJ} / \mathrm{mol}$ as the activation energy in an acetylene-oxygen mixture ( $36 \%$ dilution $\left.\mathrm{N}_{2}, 900-1600 \mathrm{~K}\right)$. As a result, we can confirm that our experiment was conducted correctly. Additionally this result implies that near-wall ignition and farwall ignition are not caused by the difference of chemical reaction mechanism, and they do not conflict with the result in Fig. 15 which indicates that ignition types behind reflected shock waves are continuous phenomena. The traveling influences of ignition positions did not cause a significant difference in the Arrhenius plot. We obtained a following equation from experimental values in the Arrhenius plot, as determined by a least-squares fit procedure:

$$
t_{\mathrm{i}}\left[\mathrm{O}_{2}\right]=A \times \exp \left(\frac{B}{T_{5 \mathrm{t}}}\right) \cdots(3)
$$


Combustion and Flame 159 (2012) 2954-2966,

H. Yamashita, J. Kasahara, Y. Sugiyama, A. Matsuo

Here, $A=2.61116 \times 10^{-7} \mu \mathrm{s} \mathrm{mol} / \mathrm{cm}^{3}$ and $B=8692.8 \mathrm{~K}$, arranging the time unit from $\mathrm{s}$ to $\mu$ s. The initial oxygen concentration $\left[\mathrm{O}_{2}\right]$ with temperature $T_{5 \mathrm{t}}$, pressure $p_{5 \mathrm{t}}$ and mole fraction $y_{\mathrm{O} 2}$ behind reflected shock waves is shown in a following equation:

$$
\left[\mathrm{O}_{2}\right]=y_{\mathrm{O} 2} \frac{p_{5 \mathrm{t}}}{R T_{5 \mathrm{t}}} \cdot \cdots(4)
$$

By substituting equation (4) into equation (3), we obtain the following equation:

$$
t_{\mathrm{i}}=\frac{A R}{y_{\mathrm{O} 2}} \times \frac{T_{5 \mathrm{t}}}{p_{5 \mathrm{t}}} \times \exp \left(\frac{B}{T_{5 \mathrm{t}}}\right) \cdot \cdot(5)
$$

By differentiating the induction time $t_{\mathrm{i}}$ with respect to temperature $T_{5 \mathrm{t}}$ on the assumption that pressure $p_{5 \mathrm{t}}$ is constant, we obtained the following equation:

$$
\left(\frac{\partial t_{\mathrm{i}}}{\partial T_{5 \mathrm{t}}}\right)_{p 5 \mathrm{t}}=\frac{A R}{y_{\mathrm{O} 2} p_{5 \mathrm{t}}} \times\left(1-\frac{B}{T_{5 \mathrm{t}}}\right) \times \exp \left(\frac{B}{T_{5 \mathrm{t}}}\right) \cdot \cdots(6)
$$

\subsection{Criterion between near-wall ignition and far-wall ignition}

Figure 20 shows the classification of phenomena (near-wall ignition, far-wall ignition and nonignition) in this study. Here, $T_{5 \mathrm{t}}$ and $p_{5 \mathrm{t}}$ are the temperature and pressure behind the reflected shock waves, respectively. The family of lines is calculated from equation (6). These lines are loci of constant gradients $\left(\left(\partial t_{\mathrm{i}} / \partial T_{5 \mathrm{t}}\right)_{p_{\mathrm{t}}}=-0.1,-0.2,-0.5,-1.0,-2.0,-5.0,-10 \mu \mathrm{s} / \mathrm{K}\right)$ of induction time with respect to temperature at constant pressure. The criterion distinguishing near-wall ignition from far-wall ignition was $-1.0 \leq\left(\partial t_{\mathrm{i}} / \partial T_{5 \mathrm{t}}\right)_{p 5 \mathrm{t}} \leq-0.5$ in Fig. 20. The line at $\left(\partial t_{\mathrm{i}} / \partial T_{5 \mathrm{t}}\right)_{p 5 \mathrm{t}}=-2.0$ shows the criterion distinguishing strong ignition from mild ignition by Mayer and Oppenheim [18]. They explained $\left(\partial t_{\mathrm{i}} / \partial T_{5 \mathrm{t}}\right)_{p 5 \mathrm{t}}$ as follows. When the absolute-value of the $\left(\partial t_{\mathrm{i}} / \partial T_{5 \mathrm{t}}\right)_{p s \mathrm{t}}$ is small, planar ignition (strong ignition) tends to occur, since the induction time is less sensitive to temperature variation. When the absolute-value of $\left(\partial t_{\mathrm{i}} / \partial T_{\mathrm{st}}\right)_{p 5 \mathrm{t}}$ is large, local ignition (mild ignition) tends to occur since the induction time is highly sensitive to temperature variation. In other words, we can see $\left(\partial t_{\mathrm{i}} / \partial T_{5 t}\right)_{p 5 t}$ as the sensitivity of induction time to non-uniformity of temperature distribution. In the present study, we 
Combustion and Flame 159 (2012) 2954-2966,

H. Yamashita, J. Kasahara, Y. Sugiyama, A. Matsuo

introduced near-wall ignition and far-wall ignition because we believe that ignition types behind reflected shock waves are continuous phenomena, and we observed a tendency for the ignition position to be located farther from the reflecting wall as the temperature decreased. Comparing these definitions between the present study and that of Mayer and Oppenheim [18], near-wall ignition corresponds to strong ignition and mild ignition whose ignition position is within $4.7 \mathrm{~mm}$ of the reflecting wall, while far-wall ignition corresponds to mild ignition whose ignition position is farther than $4.7 \mathrm{~mm}$ from the reflecting wall. Therefore, we can confirm that planar ignitions tend to occur when the absolute-value of $\left(\partial t_{\mathrm{i}} / \partial T_{5 \mathrm{t}}\right)_{p 5 \mathrm{t}}$ is small, and local ignitions tend to occur when the absolute-value of $\left(\partial t_{\mathrm{i}} / \partial T_{5 \mathrm{t}}\right)_{p 5 \mathrm{t}}$ is large, as compared to the results of Mayer and Oppenheim [18]. However, the criteria for planar ignition and local ignition are different between the present study and that of Mayer and Oppenheim [18]. We can speculate that the difference in the criteria was caused by the difference of gas mixture (in this study we used non-diluted stoichiometric acetylene-oxygen, while Mayer and Oppenheim [18] used a nondiluted stoichiometric hydrogen-oxygen mixture) or the cross-section shape of the shock tube (in this study the cross section was $50 \times 50 \mathrm{~mm}$, while that in the study of Mayer and Oppenheim [18] was $31.75 \times 44.45 \mathrm{~mm})$.

\subsection{Relation between ignition positions and gradients of induction time with respect to temperature}

Figure 21 shows the relation between ignition position $x_{\mathrm{ig}}$ and induction time gradient $\left(\partial t_{\mathrm{i}} / \partial T_{5 \mathrm{t}}\right)_{p 5 \mathrm{t}}$.

Fig. 21 presents the tendency for the ignition position to be located farther from the reflecting wall as the absolute-value of $\left(\partial t_{\mathrm{i}} / \partial T_{\mathrm{st}}\right)_{p 5 t}$ increased. That is, Fig. 21 indicates that when the absolute-value of $\left(\partial t_{\mathrm{i}} / \partial T_{5 \mathrm{t}}\right)_{p 5 \mathrm{t}}$ is large, it is easy to shorten the induction time (as shown in Fig. 7) and the temperature rise right behind the concave reflected shock waves with a distance from the reflecting wall, as shown in Fig. 8 , becomes the dominant factor in ignition phenomena because the sensitivity of the mixture to nonuniformity is high. Therefore we can predict that local ignitions at a point distant from the reflecting 
Combustion and Flame 159 (2012) 2954-2966,

H. Yamashita, J. Kasahara, Y. Sugiyama, A. Matsuo

wall from this result, as observed in Fig. 13 or proposed in Fig. 8, tend to occur at lower temperature conditions since larger absolute-value of $\left(\partial t_{\mathrm{i}} / \partial T_{5 \mathrm{t}}\right)_{p 5 \mathrm{t}}$ corresponds to lower temperature as shown in Fig. 20. This prediction dose not conflict with Fig. 15 in the experimental results and previous works [22].

\section{Conclusions}

We investigated the auto-ignitions and detonation transitions behind reflected shock waves using a numerical simulation and high-speed video camera. Based on the numerical simulation results, we proposed local ignition model induced by bifurcated shock waves and confirmed that there is no discrepancy between the proposed model and experimental results, as follows: The ignition types for each temperature range were visualized and compared with ignition types in previous studies. The tendency for ignition position to be located farther from the reflecting wall as the temperature decreased was observed and evaluated quantitatively. As experimental results, we obtained the following equation: $x_{\mathrm{ig}}=1220.9 \times T_{5 \mathrm{t}}^{-0.717}$. These results imply that ignition types behind reflected shock waves are continuous phenomena and high temperature regions shortening the induction time of combustible gases dramatically exist at a distant point from reflecting wall as shown in our proposed model. To focus our attention on the ignition positions, we classified ignition types as near-wall ignition $\left(x_{\mathrm{ig}} \leq 4.7\right)$ and farwall ignition $\left(x_{\mathrm{ig}}>4.7\right)$ based on a separating line at $x=4.7 \mathrm{~mm}$ from the reflecting wall. As visualization results, we found a tendency for ignition points to be located around the triple point trajectory and central axis of the shock tube. This tendency dose not conflict with the proposed model. On an Arrhenius plot, the activation energy of far-wall ignition was almost equal to that of near-wall ignition. Therefore, it is highly possible that near-wall ignition and far-wall ignition are not caused by a difference in the chemical reaction mechanism. This result also shows that the traveling influences of ignition positions do not cause the significant difference in the Arrhenius plot. Using the gradients of induction time with respect to temperature, the criterion differentiating near-wall ignition $\left(x_{\mathrm{ig}} \leq 4.7\right)$ from far-wall ignition $\left(x_{\mathrm{ig}}>4.7\right)$ was estimated to be $-1.0 \leq\left(\partial t_{\mathrm{i}} / \partial T_{\mathrm{st}}\right)_{p \mathrm{st}} \leq-0.5$. Additionally, comparing the 
Combustion and Flame 159 (2012) 2954-2966,

H. Yamashita, J. Kasahara, Y. Sugiyama, A. Matsuo

ignition position $x_{\mathrm{ig}}$ and induction time gradient $\left(\partial t_{\mathrm{i}} / \partial T_{5 \mathrm{t}}\right)_{p \mathrm{t}}$ in experimental results, we predicted that local ignitions at a point distant from reflecting wall tend to occur at lower temperature condition, and we confirmed that there is no discrepancy among the prediction, the our proposed model and previous works.

\section{Acknowledgements}

This work was subsidized by the Ministry of Education, Culture, Sports, Science and Technology, a Grant-in-Aid for Scientific Research (B), No. 20241040; a Grant-in-Aid for Scientific Research (A), No. 21360411; and the Research Grant Program from the Institute of Space and Astronautical Science, the Japan Aerospace Exploration Agency. Finally, the authors would like to thank S. Kato for his advice and assistance in designing and manufacturing the experimental setup. 
Combustion and Flame 159 (2012) 2954-2966,

H. Yamashita, J. Kasahara, Y. Sugiyama, A. Matsuo

\section{References}

[1] Strehlow, R.A. and Cohen, A.: Initiation of Detonation. The Physics of Fluids, 5, No. 1: 97-101 (1962)

[2] Gilbert, R.B. and Strehlow, R.A.: Theory of Detonation Initiation behind Reflected Shock Waves. AIAA Journal, 4, No. 10: 1777-1783 (1966)

[3] Strehlow, R.A.: Detonation Initiation. AIAA Journal, 2, 783 (1964)

[4] Starikovskii, A.Yu.: Ignition and Detonation in $\mathrm{N}_{2} \mathrm{O}-\mathrm{CO}-\mathrm{H}_{2}-\mathrm{He}$ Mixtures. Twenty-Sixth Symposium (International) on Combustion, 26, Issue 2, 2999-3005 (1996)

[5] Starikovskii, A.Yu.: Deflagration-To-Detonation Control by Non-Equilibrium Gas Discharges and Its Applications for Pulsed Detonation Engine. 39th AIAA/ASME/SAE/ASEE Joint Propulsion Conference and Exhibit, 2003. AIAA Paper AIAA2003-4686 (2003)

[6] Starikovskii, A.Yu.,: Development of Flows with Exothermic Reactions Behind Reflected Shock Waves. Ignition and Detonation in $\mathrm{N}_{2} \mathrm{O}-\mathrm{CO}-\mathrm{H}_{2}-\mathrm{He}$ Mixtures at High Temperatures. Chemical Physics Reports, 13 (8-9), 1422-1474 (1995)

[7] Starikovskii, A.Yu.,: Kinetics and Mechanism of Reaction in the $\mathrm{N}_{2} \mathrm{O}-\mathrm{CO}$ System at High Temperatures. Chemical Physics Reports, 13 (1), 151-190 (1994)

[8] Starikovskii, A.Yu.,: Application of Shock Tubes in High-Temperature Chemical Physics. Calculations of Thermodynamic Parameters of Gas behind the Reflected Shock Wave. Sov. Journal of Chemical Physics, 10 (9), 1911-1936 (1993)

[9] Bane, S.P.M., Ziegler, J.L. and Shepherd, J.E.: Development of One-Step Chemistry Models for Flame and Ignition Simulation. GALCIT Report GALCITFM, 002 (2010)

[10] Schultz, E. and Shepherd, J. E.: Validation of Detailed Reaction Mechanisms for Detonation Simulation. Explosion Dynamics Laboratory Report FM99-5 (2000)

[11] Varatharajan, B. and Williams, F.A.: Chemical-Kinetic Description of High-Temperature Ignition and Detonation of Acetylene-Oxygen-Diluent Systems. Combustion and Flame, 125, 624-645 (2001)

[12] Mark, H.: The Interaction of Reflected Shock Wave with the Boundary Layer in a Shock Tube. NACA Technical Memorandum 1418 (1958)

[13] Strehlow, R.A. and Cohen, A.: Limitations of the Reflected Shock Technique for Studying Fast Chemical Reactions and Its Application to the Observation of Relaxation in Nitrogen and Oxygen. The Journal of Chemical Physics, 30, No.1, 257-265 (1959)

[14] Center, R.E.: Reflected Shock Interaction with Shock Tube Boundary Layers. The Physics of Fluids, 6, No. 2: 307-308 (1963) 
Combustion and Flame 159 (2012) 2954-2966,

H. Yamashita, J. Kasahara, Y. Sugiyama, A. Matsuo

[15] Rudinger, G.: Effect of Boundary-Layer Growth in a Shock Tube on Shock Reflection from a Closed End. The Physics of Fluids, 4, No. 12: 1463-1473 (1961)

[16] Takano, Y.: Simulations of Reflected-Shock Waves in Shock Tubes Taking Account of Side-Wall Boundary-Layer Effects. The Japan Society of Mechanical Engineers, 56, 531B, 3205-3209 (1990)

[17] Voevodsky, V.V. and Soloukhin, R.I.: On the Mechanism and Explosion Limits of HydrogenOxygen Chain Self-Ignition in Shock Waves. Tenth Symposium (International) on Combustion, 279-283 (1965)

[18] Meyer, J.W. and Oppenheim, A.K.: On the Shock-Induced Ignition of Explosive Gases. Thirteenth Symposium (International) on Combustion. The Combustion Institute, Pittsburgh, 1153-1164 (1971)

[19] Meyer, J.W. and Oppenheim, A.K.: Coherence Theory of Strong Ignition Limit. Combustion and Flame, 17, 65-68 (1971)

[20] Takano, Y.: Numerical Simulations for Shock-Tube Experiments of Reflected-Shock Waves in Combustible Gas. JSME International Journal, B-36, No. 2: 300-306 (1993)

[21] Nikiforakis, N. and Clarke, J.F.: Numerical Studies of Evolution of Detonations. Mathematical and Computer Modelling, 24, No. 8, 149-164 (1996)

[22] Heufer K.A., Olivier H. Medvedev S.P. and Khomik S.V.,: 23rd International Colloquium on the Dynamics of Explosions and Reactive Systems, Paper 163 on USB flash drive (2011)

[23] Petersen, E.L. and Hanson, R.K.: Nonideal Effects behind Reflected Shock Waves in a High Pressure Shock Tube. Shock Waves, 10, 405-420 (2001)

[24] Pang, G.A., Davidson, D.F. and Hanson, R.K.: Experimental Study and Modeling of Shock Tube Ignition Delay Times for Hydrogen-Oxygen-Argon Mixtures at Low Temperatures. Proceedings of the Combustible Institute, 32, 181-188 (2009)

[25] Nicholls, J.A., Wilkinson, H.R. and Morrison, R.B.: Intermittent Detonation as a Thrust-Producing Mechanism. Jet Propulsion, 27, No. 5, 534-541 (1957)

[26] Levin, V.A., Nechaev, J.N. and Tarasov, A. I.: A New Approach to Organizing Operation Cycles in Pulsed Detonation Engines. High-Speed Deflagration and Detonation: Fundamentals and Control, Elex-KM Publ., Moscow, 223-238 (2001)

[27] Kailasanath, K.: Review of Propulsion Applications of Detonation Waves. AIAA Journal, 38, No. 9, 1698-1708 (2000)

[28] Kasahara, J., Hasegawa, A., Nemoto, T., Yamaguchi, H., Yajima, T. and Kojima, T.: Performance Validation of a Single-Tube Pulse Detonation Rocket System. Journal of Propulsion and Power, 25, No. 1, 173-180 (2009) 
Combustion and Flame 159 (2012) 2954-2966,

H. Yamashita, J. Kasahara, Y. Sugiyama, A. Matsuo

[29] Matsuoka, K., Yageta, J., Nakamichi, T., Kasahara, J., Yajima, T. and Kojima, T.: Inflow-Driven Valve System for Pulse Detonation Engines. Journal of Propulsion and Power, 27, No. 3, 597-607 (2011)

[30] Kawane, K., Shimada, S., Kasahara, J. and Matsuo, A.,: The Influence of Heat Transfer and Friction on the Impulse of Detonation Tube. Combustion and Flame, 158, 2023-2036 (2011)

[31] Endo, T., Kasahara, J., Mastuo, A., Inaba, K., Sato, S. and Fujiwara, T.: Pressure History at the Thrust Wall of a Simplified Pulse Detonation Engine. AIAA Journal, 42, 9, 1921-1930 (2004)

[32] Sato, S., Matsuo, A., Endo, T. and Kasahara, J.: Journal of Propulsion and Power, 22, No. 1, 64-69 (2006)

[34] Kasahara, J., Liang, Z., Browne, S.T. and Shepherd, J.E.: Impulse Generation by an Open Shock Tube. AIAA Journal, 46, 7, 1593-1603 (2008).

[35] Kasahara, J., Hirano, M., Matsuo, A., Daimon, Y. and Endo, T.,: Thrust Measurement of a Multicycle Partially Filled Pulse Detonation Rocket Engine. Journal of Propulsion and Power, 25, No. 6, 1281-1290 (2009)

[36] Yee, H.C.: Upwind and Symmetric Shock-capturing Schemes. NASA Technical Memorandum 89464 (1987)

[37] Kaneko, M., Men'shov, I. and Nakamura, Y.: Interaction of Reflected Shock Waves with Shock Tube Wall. Journal of the Japan Society for Aeronautical and Space Sciences, 52, No. 603, 153159 (2004)

[38] Tanaka, K.: Thermochemical Database of Gases and Condensed Materials: AISTJAN. http://riodb.ibase.aist.go.jp/ChemTherm/aistjan_e.html. Accessed 26 February 2012

[39] Edwards, D.H., Thomas, G.O. and Williams, T.L.: Initiation of Detonation by Steady Planar Incident Shock Waves. Combustion and Flame, 43, 187-198 (1981) 
Combustion and Flame 159 (2012) 2954-2966,

H. Yamashita, J. Kasahara, Y. Sugiyama, A. Matsuo

Table 1 Experimental conditions and results for the shock tube calibration. The driver gas is helium, driven gas is dry air in all shots. Initial condition error values of $p_{1}$ and $T_{1}$ are $\pm 0.1 \mathrm{kPa}$ and $\pm 0.1 \mathrm{~K}$, respectively. Analytical and systematic error values of $p_{2 \mathrm{e}}$ and $p_{5 \mathrm{e}}$ are $\pm 1 \mathrm{kPa}$.

\begin{tabular}{cccccc}
\hline $\begin{array}{c}\text { Shot } \\
\text { number }\end{array}$ & $p_{1}$ & $T_{1}$ & $\mathrm{M}_{\mathrm{si}}$ & $p_{2 \mathrm{e}}$ & $p_{5 \mathrm{e}}$ \\
- & $\mathrm{kPa}$ & $\mathrm{K}$ & - & $\mathrm{kPa}$ & $\mathrm{kPa}$ \\
\hline 1 & 5.0 & 294.7 & $2.91 \pm 0.02$ & 55 & 251 \\
2 & 2.0 & 294.7 & $3.57 \pm 0.02$ & 29 & 155 \\
3 & 2.0 & 294.7 & $3.47 \pm 0.02$ & 31 & 154 \\
4 & 2.0 & 294.7 & $3.47 \pm 0.02$ & 29 & 149 \\
5 & 2.5 & 296.3 & $3.73 \pm 0.02$ & 41 & 244 \\
6 & 3.0 & 297.2 & $3.28 \pm 0.02$ & 38 & 182 \\
7 & 3.0 & 297.2 & $3.10 \pm 0.02$ & 36 & 172 \\
8 & 6.0 & 298.2 & $2.65 \pm 0.02$ & 47 & 219 \\
9 & 10.0 & 298.2 & $2.29 \pm 0.02$ & 62 & 234 \\
10 & 10.0 & 298.2 & $2.22 \pm 0.02$ & 55 & 235 \\
11 & 10.0 & 298.2 & $2.58 \pm 0.02$ & 79 & 355 \\
12 & 10.0 & 298.2 & $1.89 \pm 0.02$ & 39 & 134 \\
13 & 10.0 & 298.2 & $1.99 \pm 0.02$ & 43 & 156 \\
14 & 10.0 & 298.2 & $1.65 \pm 0.02$ & 29 & 85 \\
15 & 10.0 & 298.2 & $1.87 \pm 0.02$ & 38 & 122 \\
16 & 10.0 & 298.2 & $2.00 \pm 0.02$ & 43 & 151 \\
17 & 10.0 & 298.2 & $2.35 \pm 0.02$ & 62 & 242 \\
\hline & & & & &
\end{tabular}


Combustion and Flame 159 (2012) 2954-2966,

H. Yamashita, J. Kasahara, Y. Sugiyama, A. Matsuo

Table 2 Experimental conditions of the near-wall ignitions. The ignition positions are within $4.7 \mathrm{~mm}$ from reflecting wall. The driver gas is helium; the driven gas (combustible mixture) is non-diluted stoichiometric acetylene-oxygen. Initial condition error values of $p_{1}$ and $T_{1}$ are $\pm 1 \mathrm{kPa}$ and $\pm 0.1 \mathrm{~K}$, respectively.

\begin{tabular}{cccccc}
\hline $\begin{array}{c}\text { shot } \\
\text { number }\end{array}$ & $p_{1}$ & $T_{1}$ & $\mathrm{M}_{\mathrm{si}}$ & $p_{5 \mathrm{t}}$ & $T_{5 \mathrm{t}}$ \\
& $\mathrm{kPa}$ & $\mathrm{K}$ & - & $\mathrm{kPa}$ & $\mathrm{K}$ \\
\hline 18 & 2.5 & 299.7 & $3.11 \pm 0.02$ & $148 \pm 10$ & $1291 \pm 16$ \\
19 & 2.5 & 299.7 & $3.06 \pm 0.02$ & $142 \pm 10$ & $1259 \pm 19$ \\
20 & 2.5 & 299.7 & $3.01 \pm 0.02$ & $135 \pm 9$ & $1226 \pm 16$ \\
21 & 2.5 & 299.7 & $2.84 \pm 0.02$ & $114 \pm 8$ & $1115 \pm 15$ \\
22 & 2.5 & 299.7 & $2.72 \pm 0.02$ & $100 \pm 7$ & $1043 \pm 14$ \\
23 & 2.5 & 301.8 & $2.95 \pm 0.08$ & $127 \pm 15$ & $1195 \pm 53$ \\
24 & 2.0 & 293.0 & $2.88 \pm 0.02$ & $96 \pm 2$ & $1120 \pm 11$ \\
25 & 2.0 & 293.7 & $3.04 \pm 0.02$ & $111 \pm 2$ & $1219 \pm 11$ \\
26 & 2.0 & 294.2 & $3.23 \pm 0.02$ & $132 \pm 2$ & $1349 \pm 11$ \\
27 & 2.0 & 294.2 & $3.01 \pm 0.02$ & $108 \pm 2$ & $1205 \pm 14$ \\
28 & 2.0 & 294.2 & $3.12 \pm 0.02$ & $120 \pm 2$ & $1273 \pm 12$ \\
29 & 1.5 & 291.2 & $2.93 \pm 0.02$ & $75 \pm 2$ & $1144 \pm 11$ \\
30 & 3.0 & 292.7 & $2.86 \pm 0.02$ & $139 \pm 2$ & $1101 \pm 11$ \\
31 & 3.0 & 293.2 & $2.84 \pm 0.02$ & $137 \pm 2$ & $1091 \pm 10$ \\
32 & 3.5 & 290.7 & $2.88 \pm 0.02$ & $168 \pm 3$ & $1112 \pm 12$ \\
33 & 3.0 & 292.2 & $2.72 \pm 0.02$ & $121 \pm 2$ & $1019 \pm 10$ \\
\hline
\end{tabular}


Combustion and Flame 159 (2012) 2954-2966,

H. Yamashita, J. Kasahara, Y. Sugiyama, A. Matsuo

Table 3 Experimental conditions of the far-wall ignitions. The ignition positions are farther than $4.7 \mathrm{~mm}$ from reflecting wall. The driver gas is helium; the driven gas (combustible mixture) is non-diluted stoichiometric acetylene-oxygen. Initial condition error values of $p_{1}$ and $T_{1}$ are $\pm 1 \mathrm{kPa}$ and $\pm 0.1 \mathrm{~K}$, respectively.

\begin{tabular}{cccccc}
\hline $\begin{array}{c}\text { shot } \\
\text { number }\end{array}$ & $p_{1}$ & $T_{1}$ & $\mathrm{M}_{\mathrm{si}}$ & $p_{5 \mathrm{t}}$ & $T_{5 \mathrm{t}}$ \\
& $\mathrm{kPa}$ & $\mathrm{K}$ & - & $\mathrm{kPa}$ & $\mathrm{K}$ \\
\hline 34 & 5.0 & 300.0 & $2.71 \pm 0.04$ & $199 \pm 11$ & $1040 \pm 24$ \\
35 & 5.0 & 300.0 & $2.73 \pm 0.04$ & $203 \pm 13$ & $1052 \pm 24$ \\
36 & 3.0 & 292.7 & $2.74 \pm 0.02$ & $123 \pm 3$ & $1031 \pm 11$ \\
37 & 3.0 & 292.7 & $2.81 \pm 0.03$ & $133 \pm 2$ & $1072 \pm 12$ \\
38 & 2.0 & 292.2 & $2.80 \pm 0.03$ & $88 \pm 2$ & $1068 \pm 13$ \\
39 & 2.0 & 292.2 & $2.73 \pm 0.03$ & $81 \pm 3$ & $1025 \pm 13$ \\
40 & 1.5 & 293.1 & $2.80 \pm 0.02$ & $66 \pm 2$ & $1068 \pm 10$ \\
41 & 1.5 & 292.2 & $2.71 \pm 0.02$ & $60 \pm 2$ & $1014 \pm 10$ \\
42 & 1.5 & 292.7 & $2.66 \pm 0.02$ & $56 \pm 2$ & $987 \pm 6$ \\
43 & 2.5 & 301.8 & $2.56 \pm 0.03$ & $83 \pm 7$ & $956 \pm 13$ \\
44 & 2.5 & 293.2 & $2.69 \pm 0.02$ & $97 \pm 2$ & $1007 \pm 5$ \\
45 & 2.5 & 293.7 & $2.66 \pm 0.02$ & $94 \pm 2$ & $988 \pm 7$ \\
46 & 3.5 & 295.7 & $2.54 \pm 0.02$ & $114 \pm 2$ & $927 \pm 7$ \\
47 & 3.5 & 295.7 & $2.71 \pm 0.02$ & $140 \pm 3$ & $1027 \pm 9$ \\
48 & 3.5 & 292.9 & $2.63 \pm 0.02$ & $127 \pm 2$ & $969 \pm 8$ \\
49 & 3.5 & 293.2 & $2.64 \pm 0.02$ & $129 \pm 2$ & $977 \pm 6$ \\
50 & 3.0 & 291.2 & $2.74 \pm 0.02$ & $123 \pm 2$ & $1025 \pm 7$ \\
51 & 3.0 & 291.5 & $2.74 \pm 0.02$ & $123 \pm 2$ & $1025 \pm 7$ \\
52 & 3.0 & 292.2 & $2.78 \pm 0.02$ & $128 \pm 3$ & $1051 \pm 12$ \\
53 & 2.0 & 290.2 & $2.81 \pm 0.03$ & $89 \pm 3$ & $1066 \pm 13$ \\
54 & 2.0 & 299.6 & $2.56 \pm 0.06$ & $67 \pm 5$ & $953 \pm 16$ \\
55 & 5.0 & 297.0 & $2.36 \pm 0.12$ & $130 \pm 23$ & $838 \pm 62$ \\
56 & 2.5 & 293.2 & $2.58 \pm 0.02$ & $86 \pm 2$ & $945 \pm 6$ \\
57 & 3.5 & 294.2 & $2.56 \pm 0.02$ & $118 \pm 2$ & $937 \pm 8$ \\
58 & 3.0 & 293.2 & $2.61 \pm 0.02$ & $107 \pm 2$ & $961 \pm 6$ \\
59 & 3.0 & 293.2 & $2.58 \pm 0.02$ & $103 \pm 2$ & $943 \pm 7$ \\
\hline & & & & &
\end{tabular}


Combustion and Flame 159 (2012) 2954-2966,

H. Yamashita, J. Kasahara, Y. Sugiyama, A. Matsuo

Table 4 Experimental conditions of the non-ignition. The driver gas is helium; the driven gas (combustible mixture) is non-diluted stoichiometric acetylene-oxygen. Initial condition error values of $p_{1}$ and $T_{1}$ are $\pm 1 \mathrm{kPa}$ and $\pm 0.1 \mathrm{~K}$, respectively.

\begin{tabular}{cccccc}
\hline $\begin{array}{c}\text { shot } \\
\text { number }\end{array}$ & $p_{1}$ & $T_{1}$ & $\mathrm{M}_{\mathrm{si}}$ & $p_{5 \mathrm{t}}$ & $T_{5 \mathrm{t}}$ \\
& $\mathrm{kPa}$ & $\mathrm{K}$ & - & $\mathrm{kPa}$ & $\mathrm{K}$ \\
\hline 60 & 2.5 & 301.8 & $2.38 \pm 0.02$ & $66 \pm 5$ & $859 \pm 12$ \\
61 & 5.0 & 299.1 & $2.14 \pm 0.12$ & $94 \pm 11$ & $732 \pm 59$ \\
62 & 5.0 & 300.0 & $2.44 \pm 0.04$ & $143 \pm 12$ & $885 \pm 16$ \\
63 & 10.0 & 300.0 & $1.99 \pm 0.04$ & $148 \pm 12$ & $666 \pm 18$ \\
64 & 10.0 & 300.0 & $1.98 \pm 0.04$ & $146 \pm 12$ & $662 \pm 18$ \\
65 & 5.0 & 297.0 & $2.38 \pm 0.03$ & $133 \pm 8$ & $847 \pm 15$ \\
66 & 5.0 & 290.2 & $2.35 \pm 0.02$ & $128 \pm 2$ & $814 \pm 5$ \\
67 & 2.5 & 290.2 & $2.54 \pm 0.02$ & $81 \pm 2$ & $910 \pm 6$ \\
68 & 2.5 & 293.7 & $2.39 \pm 0.02$ & $68 \pm 2$ & $843 \pm 6$ \\
69 & 2.5 & 293.7 & $2.56 \pm 0.02$ & $84 \pm 2$ & $934 \pm 6$ \\
70 & 3.5 & 293.2 & $2.25 \pm 0.02$ & $78 \pm 2$ & $771 \pm 7$ \\
71 & 3.5 & 291.7 & $2.47 \pm 0.02$ & $105 \pm 2$ & $881 \pm 7$ \\
72 & 3.5 & 295.2 & $2.47 \pm 0.02$ & $104 \pm 2$ & $886 \pm 9$ \\
73 & 3.5 & 293.2 & $2.36 \pm 0.02$ & $91 \pm 2$ & $827 \pm 6$ \\
74 & 3.5 & 290.7 & $1.76 \pm 0.02$ & $34 \pm 2$ & $549 \pm 10$ \\
75 & 3.0 & 293.2 & $2.24 \pm 0.02$ & $66 \pm 2$ & $768 \pm 7$ \\
76 & 3.0 & 293.2 & $2.25 \pm 0.01$ & $66 \pm 26$ & $769 \pm 6$ \\
77 & 3.0 & 293.2 & $2.43 \pm 0.02$ & $85 \pm 2$ & $862 \pm 6$ \\
78 & 2.5 & 294.7 & $2.46 \pm 0.02$ & $74 \pm 2$ & $882 \pm 10$ \\
79 & 2.5 & 291.2 & $2.41 \pm 0.03$ & $69 \pm 3$ & $846 \pm 11$ \\
\hline
\end{tabular}


Combustion and Flame 159 (2012) 2954-2966,

H. Yamashita, J. Kasahara, Y. Sugiyama, A. Matsuo
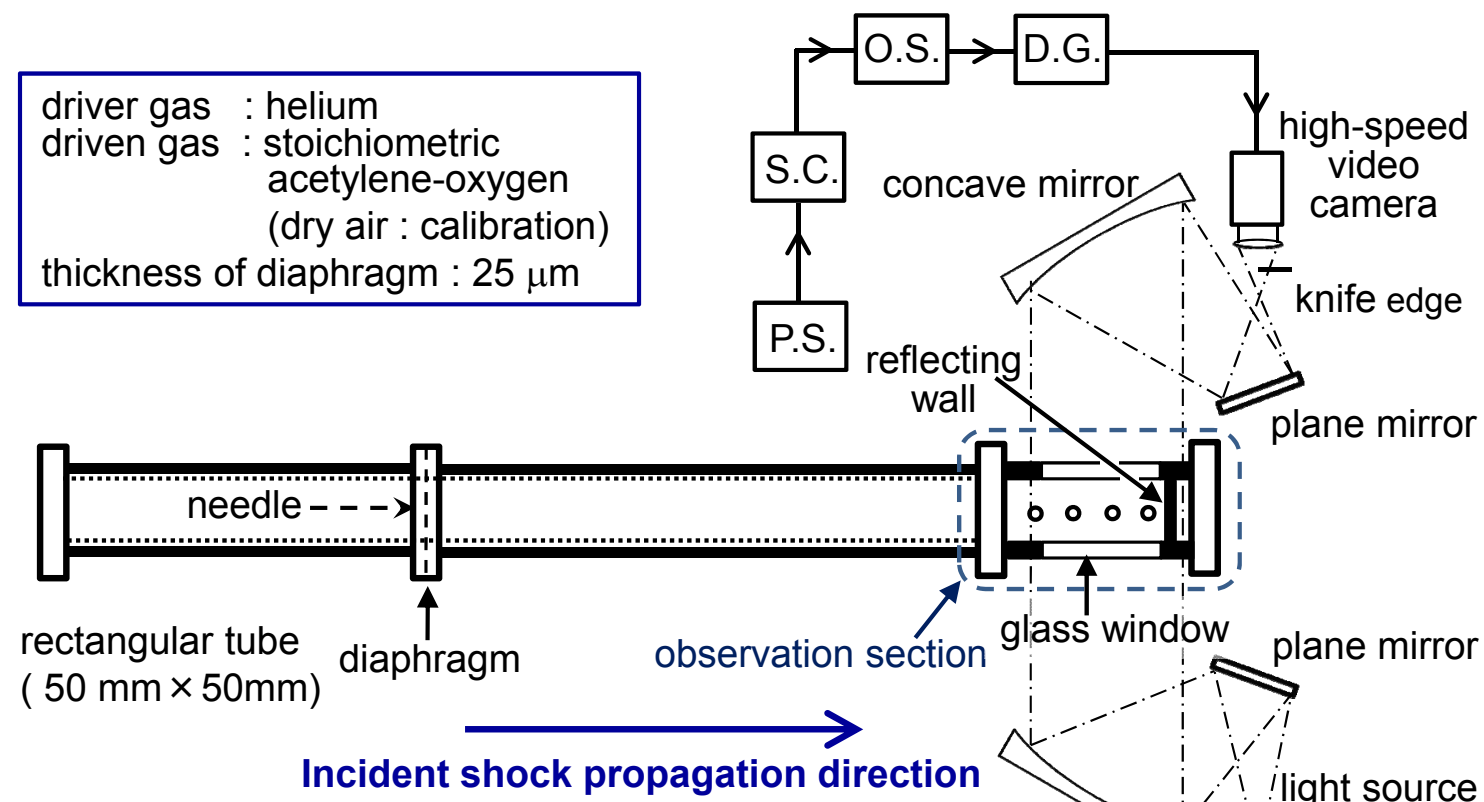

plane mirror

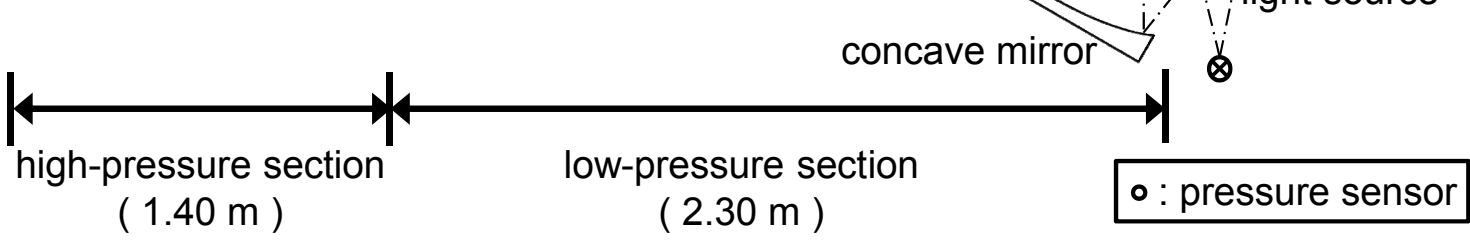

Fig. 1 Overall view of the experimental system.

P.S.: pressure sensor, S.C.: signal conditioner, O.S.: oscilloscope, D.G.: delay generator 
Combustion and Flame 159 (2012) 2954-2966,

H. Yamashita, J. Kasahara, Y. Sugiyama, A. Matsuo

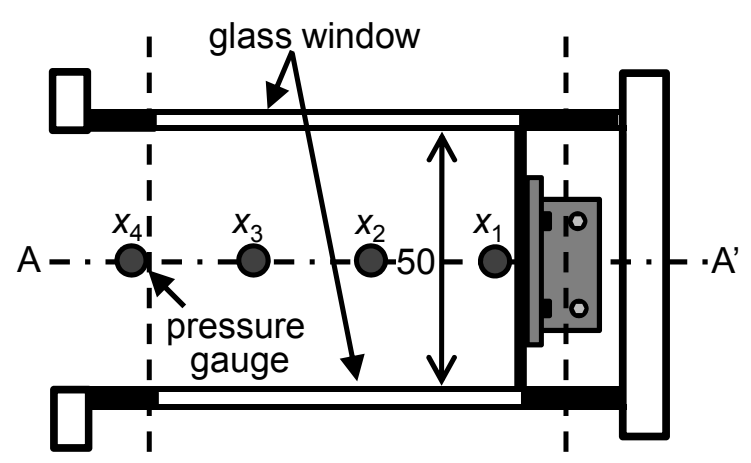

(1) top view of observation section



(2) A-A' cut plane

Fig. 2 Schematic illustration of the observation section. 
Combustion and Flame 159 (2012) 2954-2966,

H. Yamashita, J. Kasahara, Y. Sugiyama, A. Matsuo

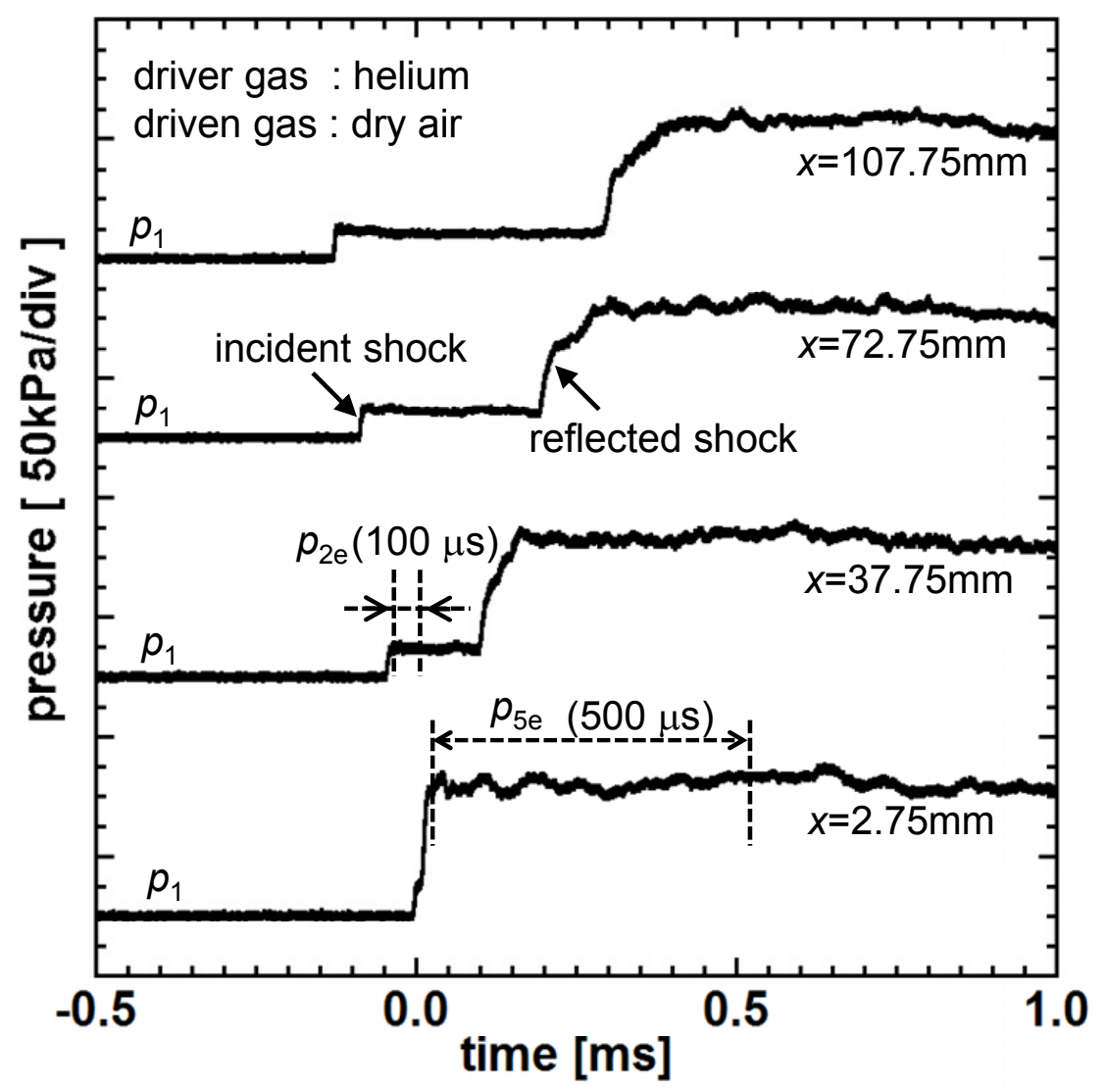

Fig. 3 Definition of $p_{2 \mathrm{e}}$ and $p_{5 \mathrm{e}}$ on pressure histories in shot8. Experimental conditions are $p_{1}=6.0 \pm 0.1$ $\mathrm{kPa}, T_{1}=298.2 \pm 0.1 \mathrm{kPa}$ and $\mathrm{M}_{\mathrm{si}}=2.65 \pm 0.02$, respectively. 
Combustion and Flame 159 (2012) 2954-2966,

H. Yamashita, J. Kasahara, Y. Sugiyama, A. Matsuo

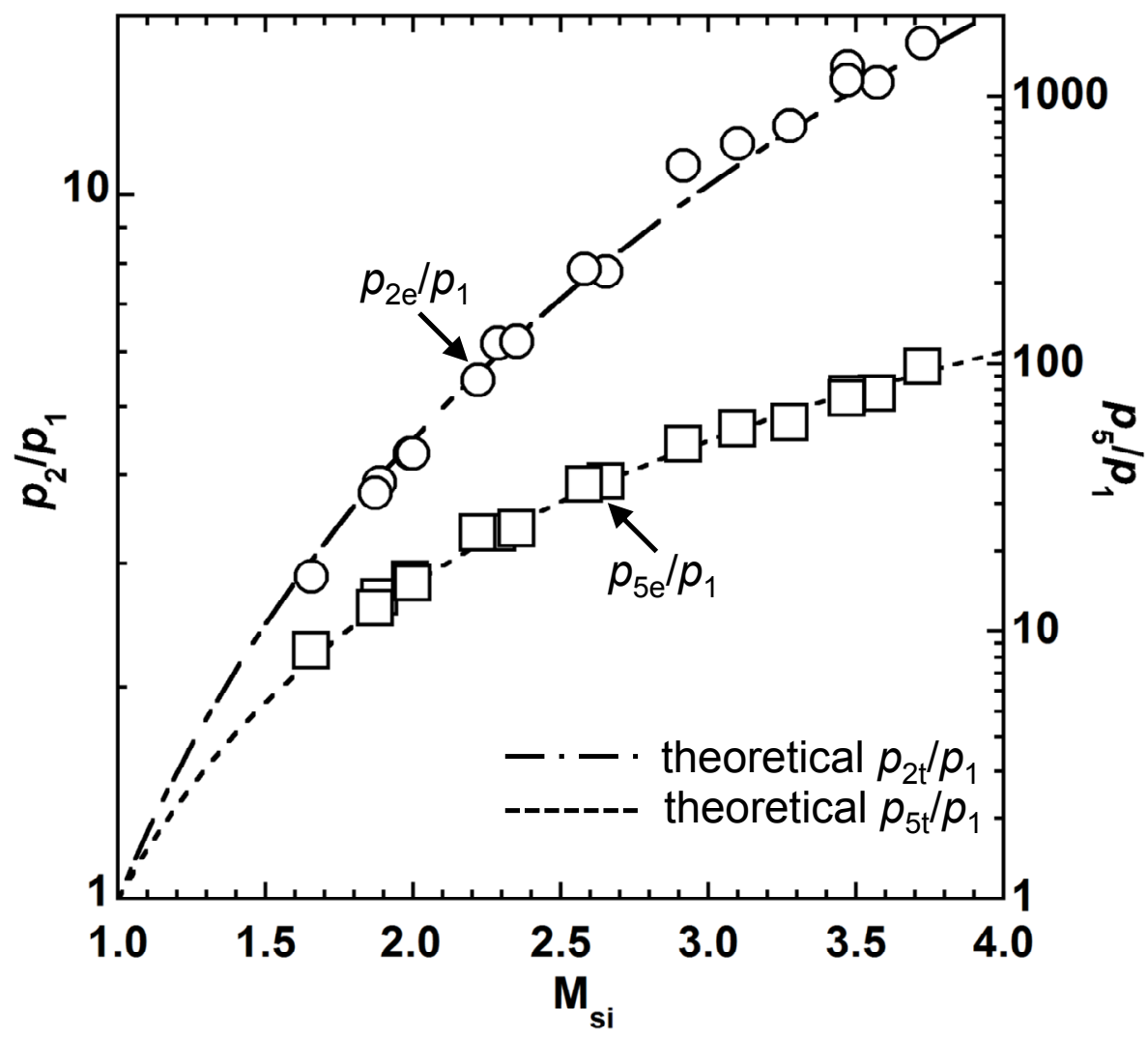

Fig. 4 Calibration results of the shock tube. Plots are experimental value $p_{2 \mathrm{e}} / p_{1}, p_{5 \mathrm{e}} / p_{1}$, and the dashed line means theoretical values $p_{2 t} / p_{1}, p_{5 t} / p_{1}$ calculated by Rankine-Hugoniot equations with assumption based on a perfect gas. 
Combustion and Flame 159 (2012) 2954-2966,

H. Yamashita, J. Kasahara, Y. Sugiyama, A. Matsuo
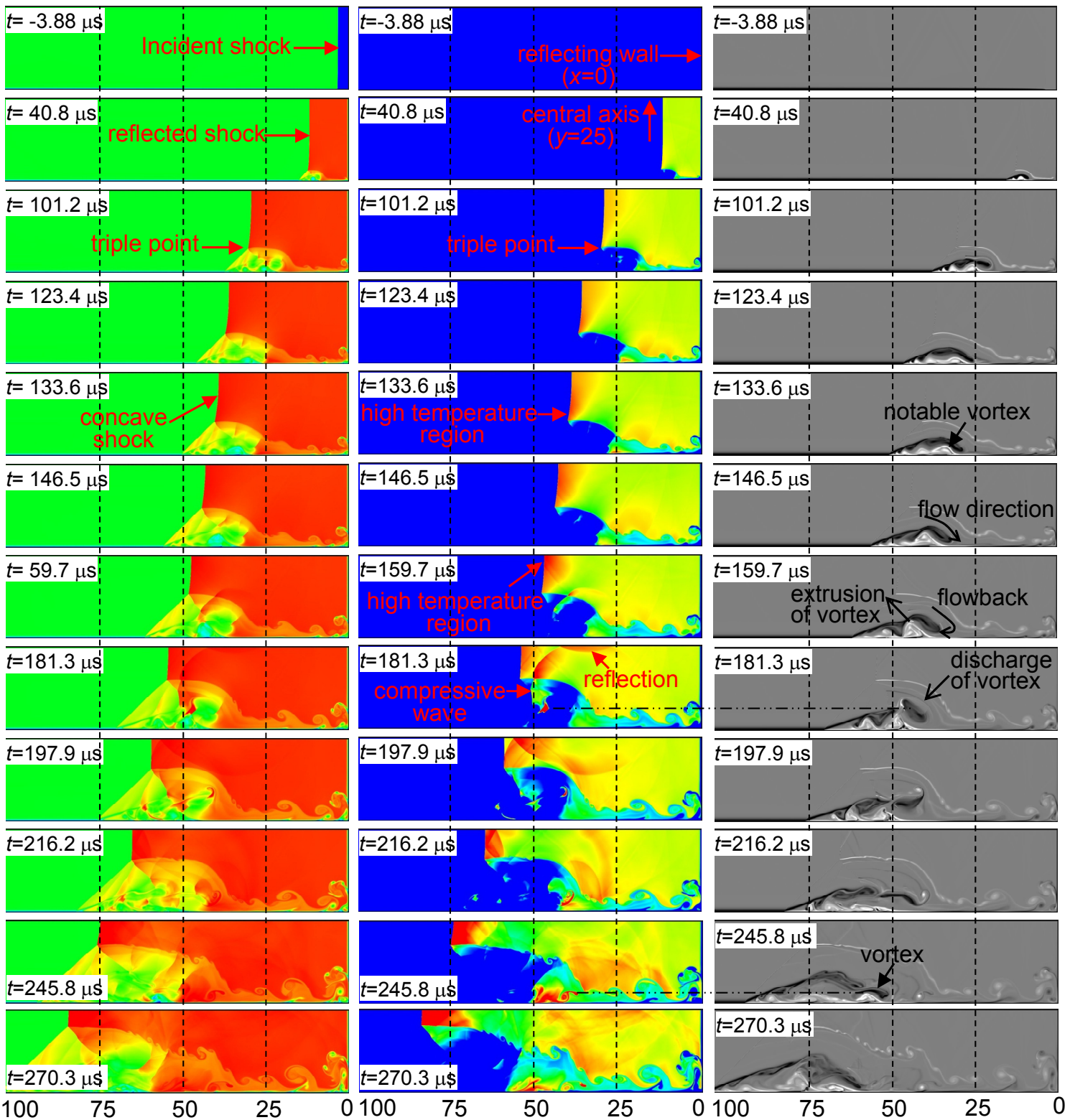
(a) 300 temperature $[\mathrm{K}]$

(b) 800 temperature $[\mathrm{K}]$

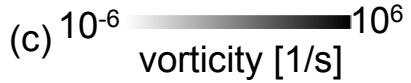

Fig. 5 Temperature and vorticity distribution around the reflecting wall in the numerical simulations. This numerical simulation was conducted under the same conditions as shot 54 , in which we observed local ignition at some distance from the reflecting wall $\left(\mathrm{M}_{\mathrm{si}}=2.56, p_{5 \mathrm{t}}=67 \pm 5 \mathrm{kPa}, T_{5 \mathrm{t}}=953 \pm 16 \mathrm{~K}, t_{\mathrm{i}}=\right.$ $276 \pm 2 \mu \mathrm{s}, x_{\mathrm{ig}}=28.9 \pm 0.3 \mathrm{~mm}$ ). Here, $t=0$ is the reflection time of incident shock waves. 
Combustion and Flame 159 (2012) 2954-2966,

H. Yamashita, J. Kasahara, Y. Sugiyama, A. Matsuo



Fig. 6 Time variation of temperature behind reflected shock waves and the velocity at the center of reflected shock waves. The $t=0$ is the reflection time of incident shock waves. The symbol $T_{5 \mathrm{~s}}$ and $U_{\mathrm{rs}}$ are simulated temperature right behind the reflected shock and velocity of reflected shock on the central axis of shock tube, respectively. 
Combustion and Flame 159 (2012) 2954-2966,

H. Yamashita, J. Kasahara, Y. Sugiyama, A. Matsuo

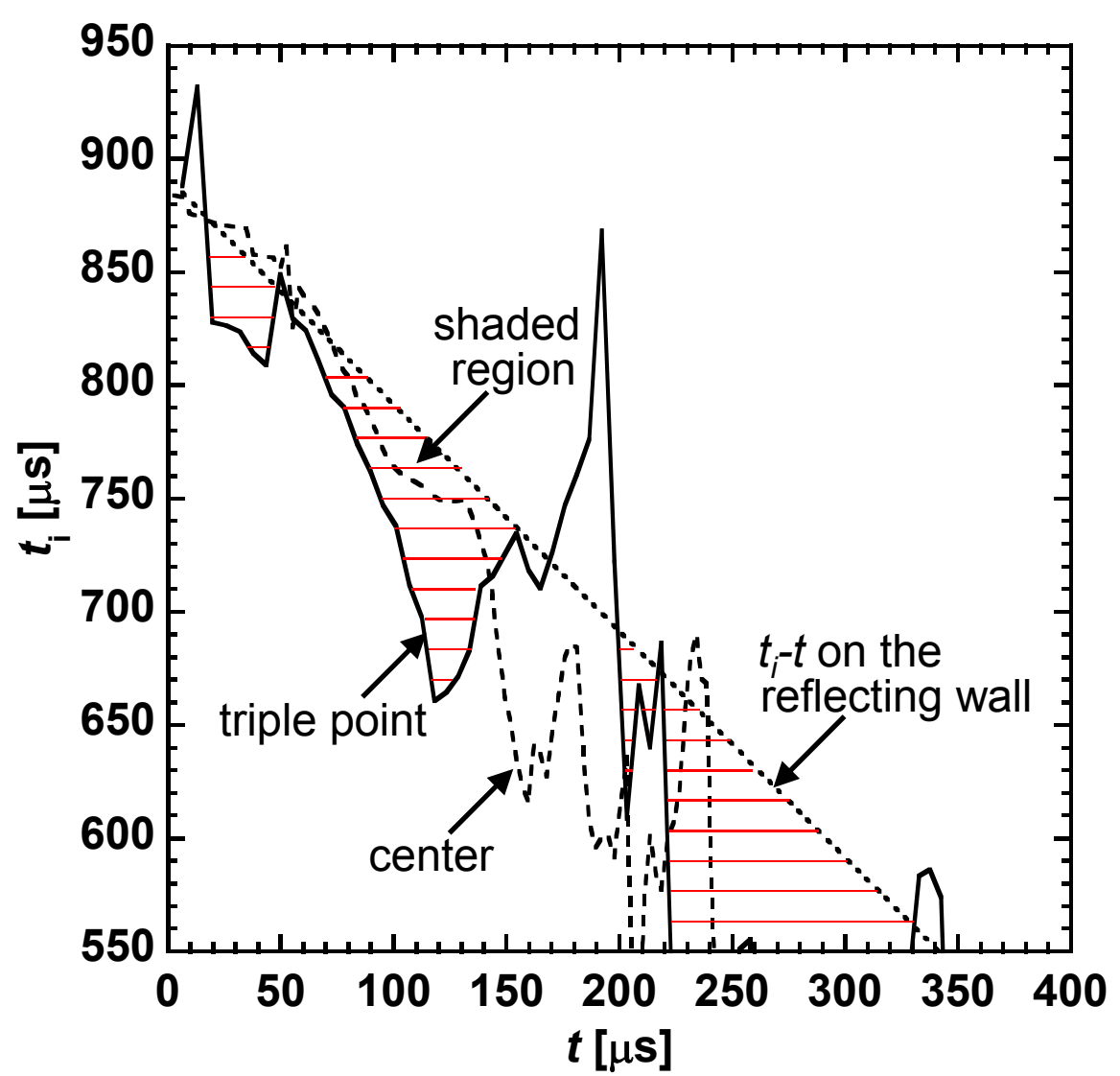

Fig. 7 Comparison between $t_{\mathrm{i}}-t$ on the reflecting wall and $t_{\mathrm{i}}$ behind bifurcated shock waves. The linear dashed line shows $t_{\mathrm{i}}-t$ on the reflecting wall. The solid line and other line shows $t_{\mathrm{i}}$ estimated from experimental equation (5) assuming the temperature behind the triple point and center of reflected shock waves. The shaded regions have the possibility that distant ignitions from reflecting wall occur because of shortening of induction time. 
Combustion and Flame 159 (2012) 2954-2966,

H. Yamashita, J. Kasahara, Y. Sugiyama, A. Matsuo

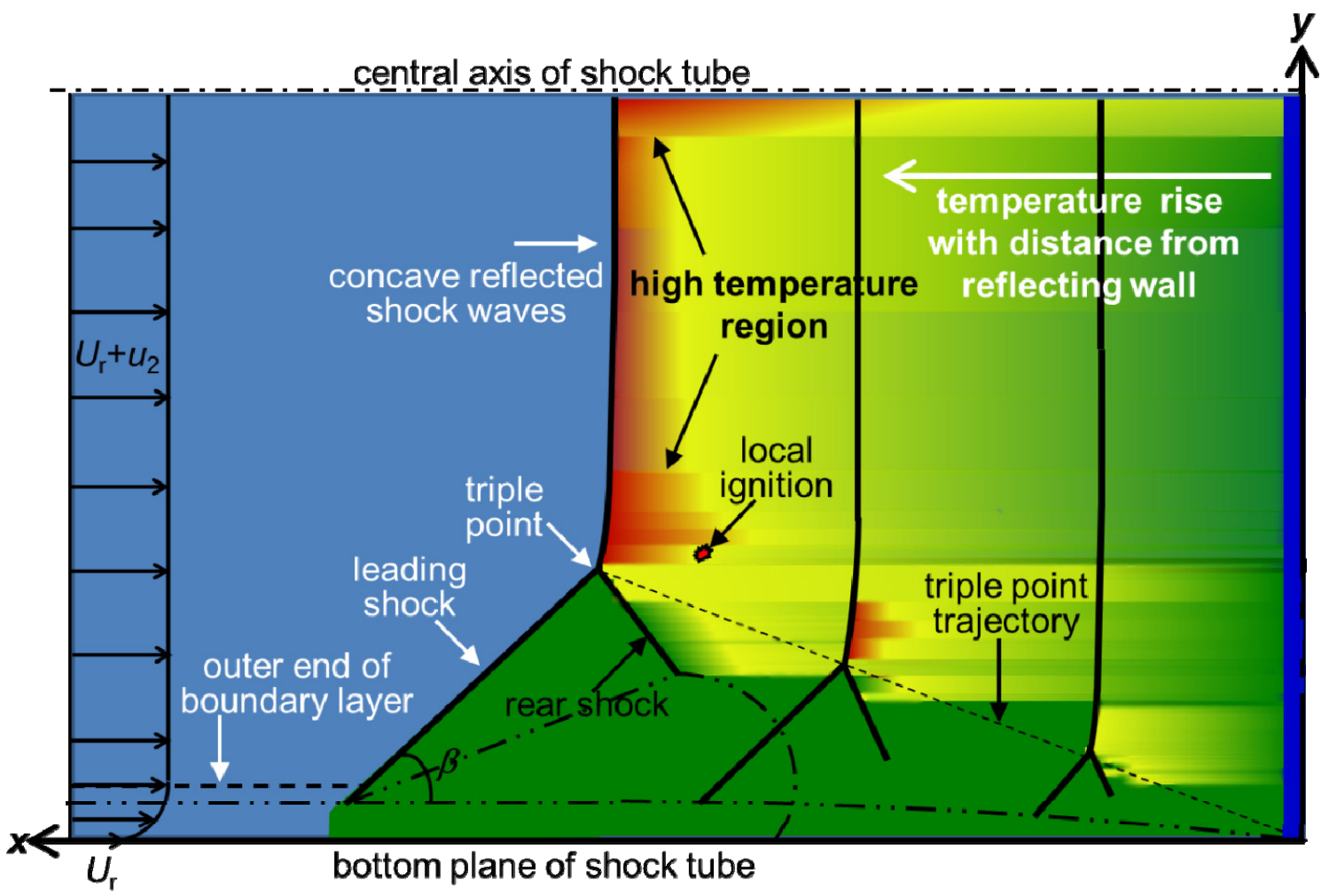

Fig. 8 Proposed model of local ignitions induced by bifurcated shock waves. The traveling of the ignition position is induced by temperature rise (red-painted regions) right behind concave reflected shock waves with distance from the reflecting wall. The high and low temperature regions are painted by red and blue, respectively. 
Combustion and Flame 159 (2012) 2954-2966,

H. Yamashita, J. Kasahara, Y. Sugiyama, A. Matsuo
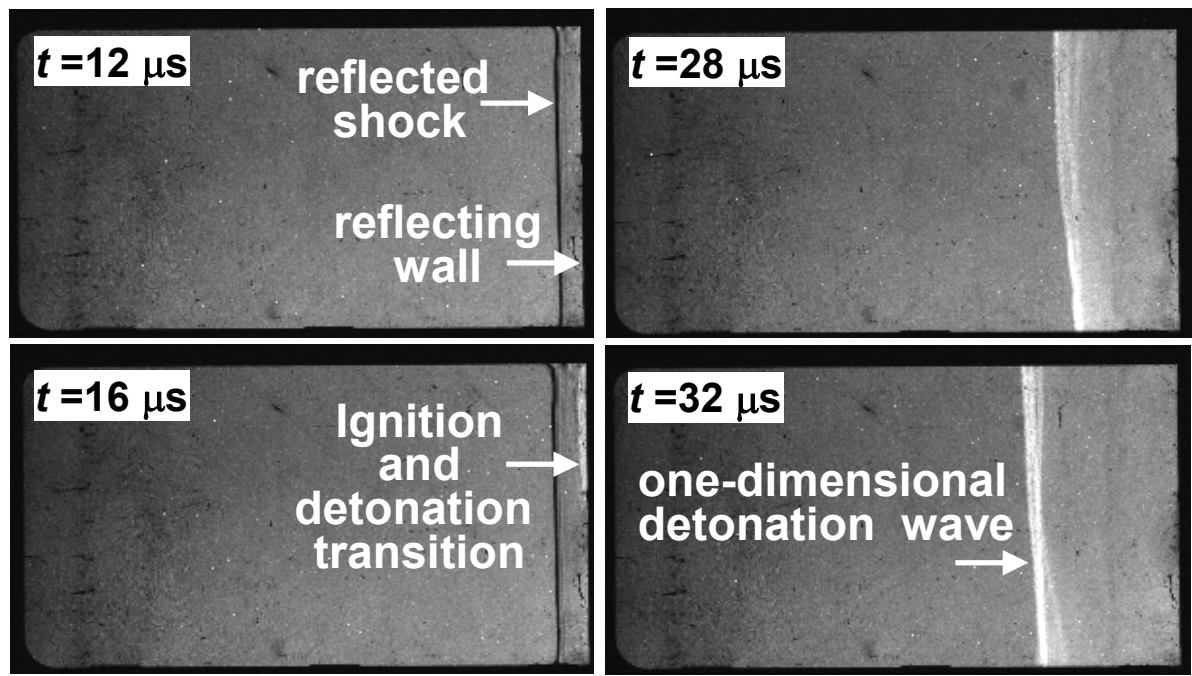

$t=32 \mu \mathrm{s}$


$$
t=24 \mu s
$$

$t=32 \mu \mathrm{s}$
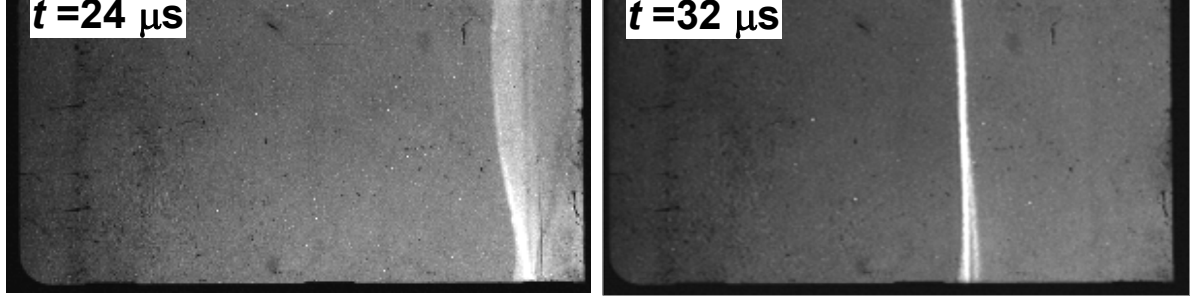

Fig. 9 Schlieren results of auto-ignitions and detonation transitions. The conditions behind the reflected shock waves are $p_{5 \mathrm{t}}=148 \pm 10 \mathrm{kPa}, T_{5 \mathrm{t}}=1291 \pm 16 \mathrm{~K}, t_{\mathrm{i}}=16 \mu \mathrm{s}$ ( $($ hot 18$)$. 
Combustion and Flame 159 (2012) 2954-2966,

H. Yamashita, J. Kasahara, Y. Sugiyama, A. Matsuo
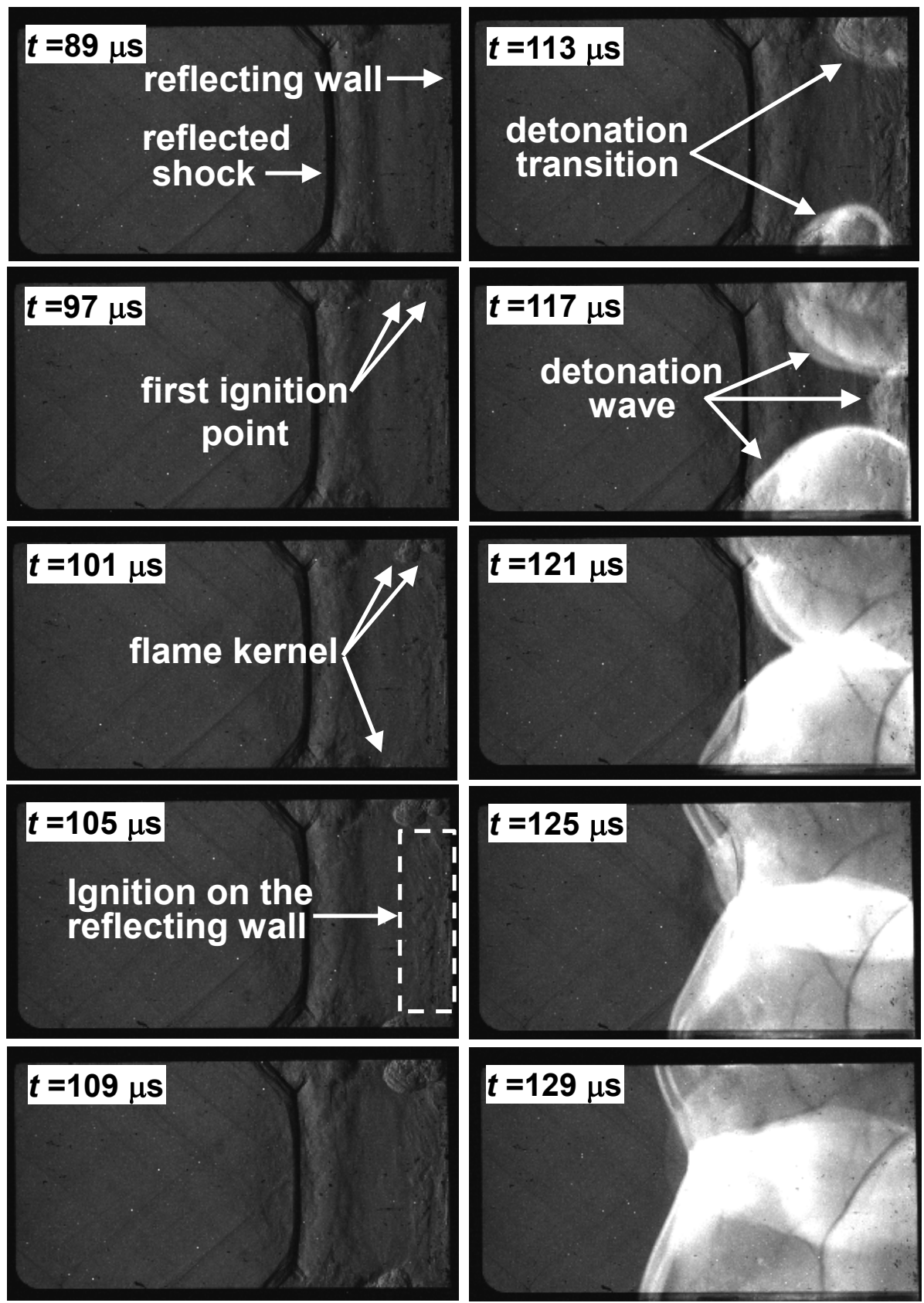

Fig. 10 Schlieren results of auto-ignitions and detonation transitions. The conditions behind the reflected shock waves are $p_{5 \mathrm{t}}=123 \pm 3 \mathrm{kPa}, T_{5 \mathrm{t}}=1031 \pm 11 \mathrm{~K}, t_{\mathrm{i}}=64 \pm 2 \mu \mathrm{s}(\operatorname{shot} 36)$. 
Combustion and Flame 159 (2012) 2954-2966,

H. Yamashita, J. Kasahara, Y. Sugiyama, A. Matsuo
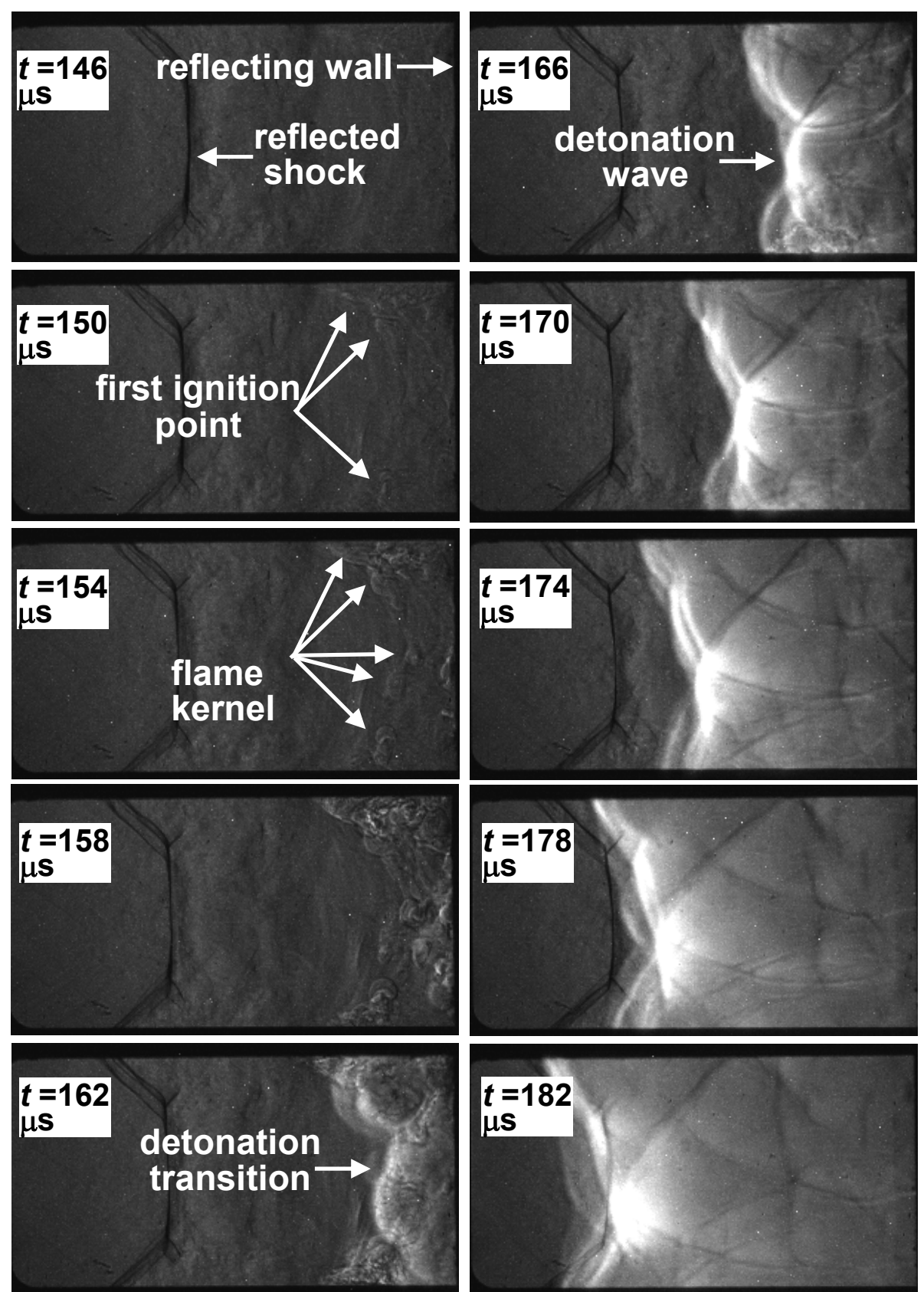

Fig. 11 Schlieren results of auto-ignitions and detonation transitions. The conditions behind the reflected shock waves are $p_{5 \mathrm{t}}=81 \pm 3 \mathrm{kPa}, T_{5 \mathrm{t}}=1025 \pm 13 \mathrm{~K}, t_{\mathrm{i}}=150 \pm 2 \mu \mathrm{s}$ (shot39). 
Combustion and Flame 159 (2012) 2954-2966,

H. Yamashita, J. Kasahara, Y. Sugiyama, A. Matsuo
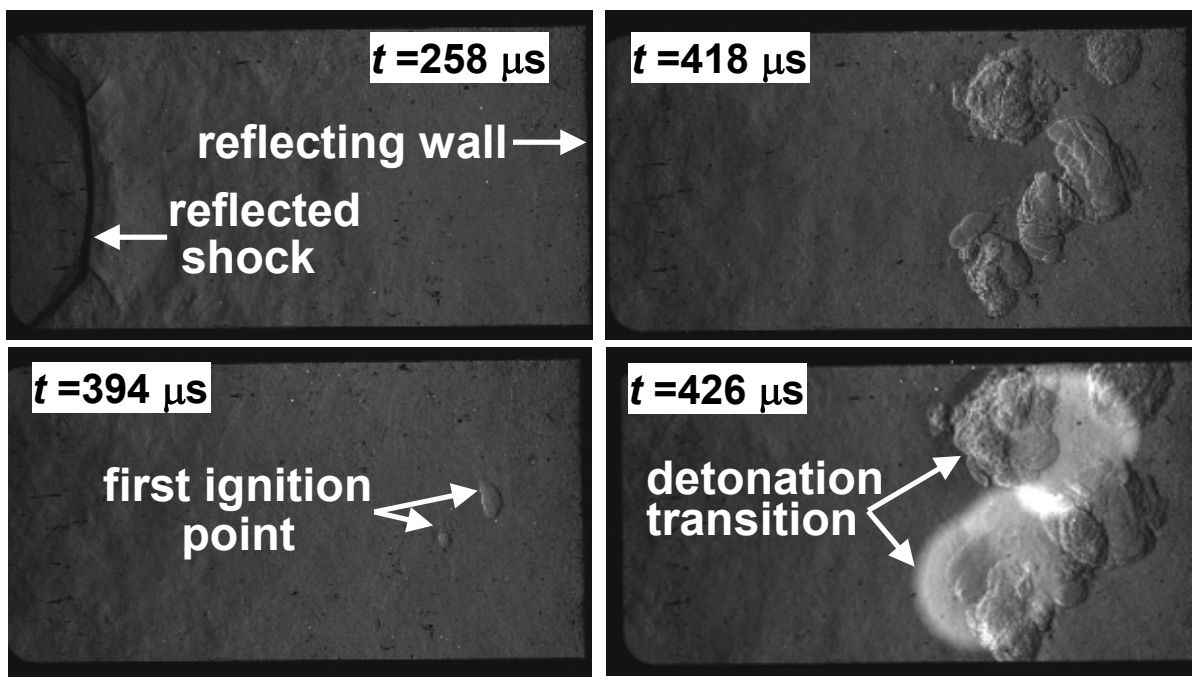

$$
t=402 \mu s
$$


Fig. 12 Schlieren results of auto-ignitions and detonation transitions. The conditions behind the reflected shock waves are $p_{5 \mathrm{t}}=94 \pm 2 \mathrm{kPa}, T_{5 \mathrm{t}}=988 \pm 7 \mathrm{~K}, t_{\mathrm{i}}=340 \pm 4 \mu \mathrm{s}$ (shot 45 ). 
Combustion and Flame 159 (2012) 2954-2966,

H. Yamashita, J. Kasahara, Y. Sugiyama, A. Matsuo


$$
t=374 \mu \mathrm{s}
$$
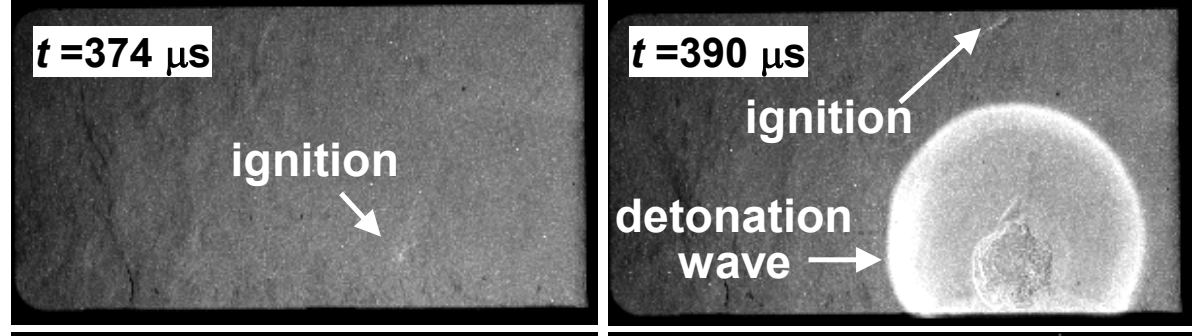

$$
t=378 \mu \mathrm{s}
$$

\section{flame kernel}



$$
t=382 \mu \mathrm{s}
$$


\section{$t=398 \mu \mathrm{s}$}

Fig. 13 Schlieren results of auto-ignitions and detonation transitions. The conditions behind the reflected shock waves are $p_{5 \mathrm{t}}=67 \pm 5 \mathrm{kPa}, T_{5 \mathrm{t}}=953 \pm 16 \mathrm{~K}, t_{\mathrm{i}}=276 \pm 2 \mu \mathrm{s}$ (shot54). 
Combustion and Flame 159 (2012) 2954-2966,

H. Yamashita, J. Kasahara, Y. Sugiyama, A. Matsuo
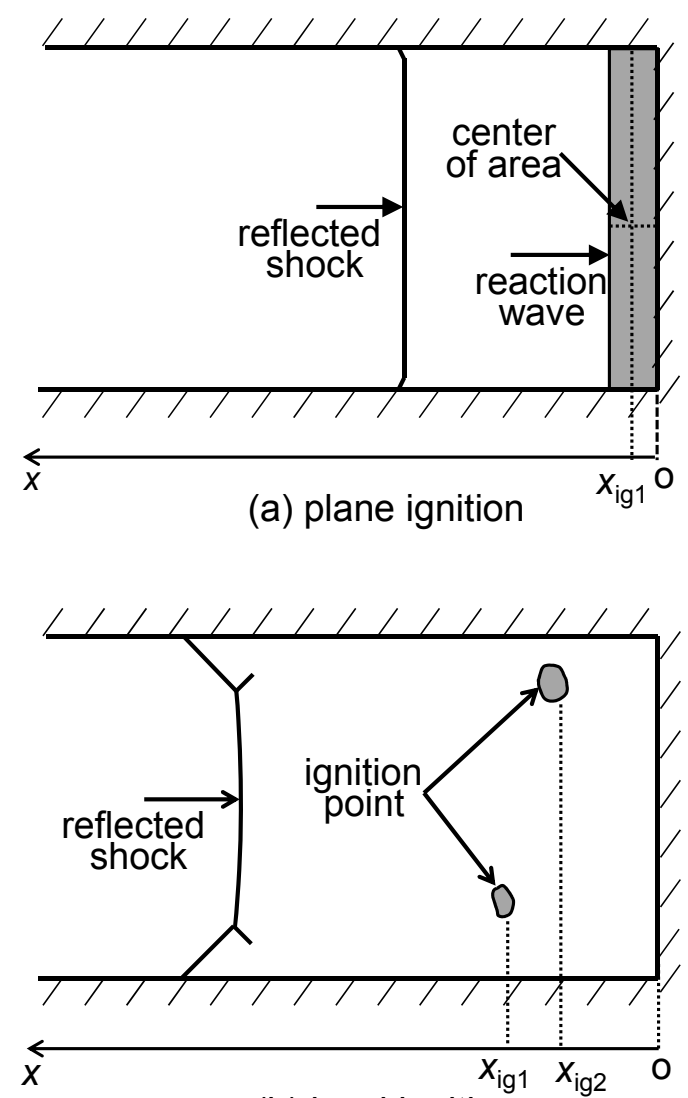

(b) local ignition

Fig. 14 Definition of ignition position $x_{\mathrm{ig}}\left(x_{\mathrm{ig}}=\sum_{\mathrm{j}=1}^{\mathrm{n}} x_{\mathrm{igj}} / \mathrm{n}\right)$. 
Combustion and Flame 159 (2012) 2954-2966,

H. Yamashita, J. Kasahara, Y. Sugiyama, A. Matsuo



Fig. 15 Relation between $x_{\text {ig }}$ and $T_{5 \mathrm{t}}$. The symbol $x_{\mathrm{ig}}$ indicates the ignition position defined in Fig. 14. The symbol $T_{5 \mathrm{t}}$ indicates the temperature behind reflected shock waves. 
Combustion and Flame 159 (2012) 2954-2966,

H. Yamashita, J. Kasahara, Y. Sugiyama, A. Matsuo

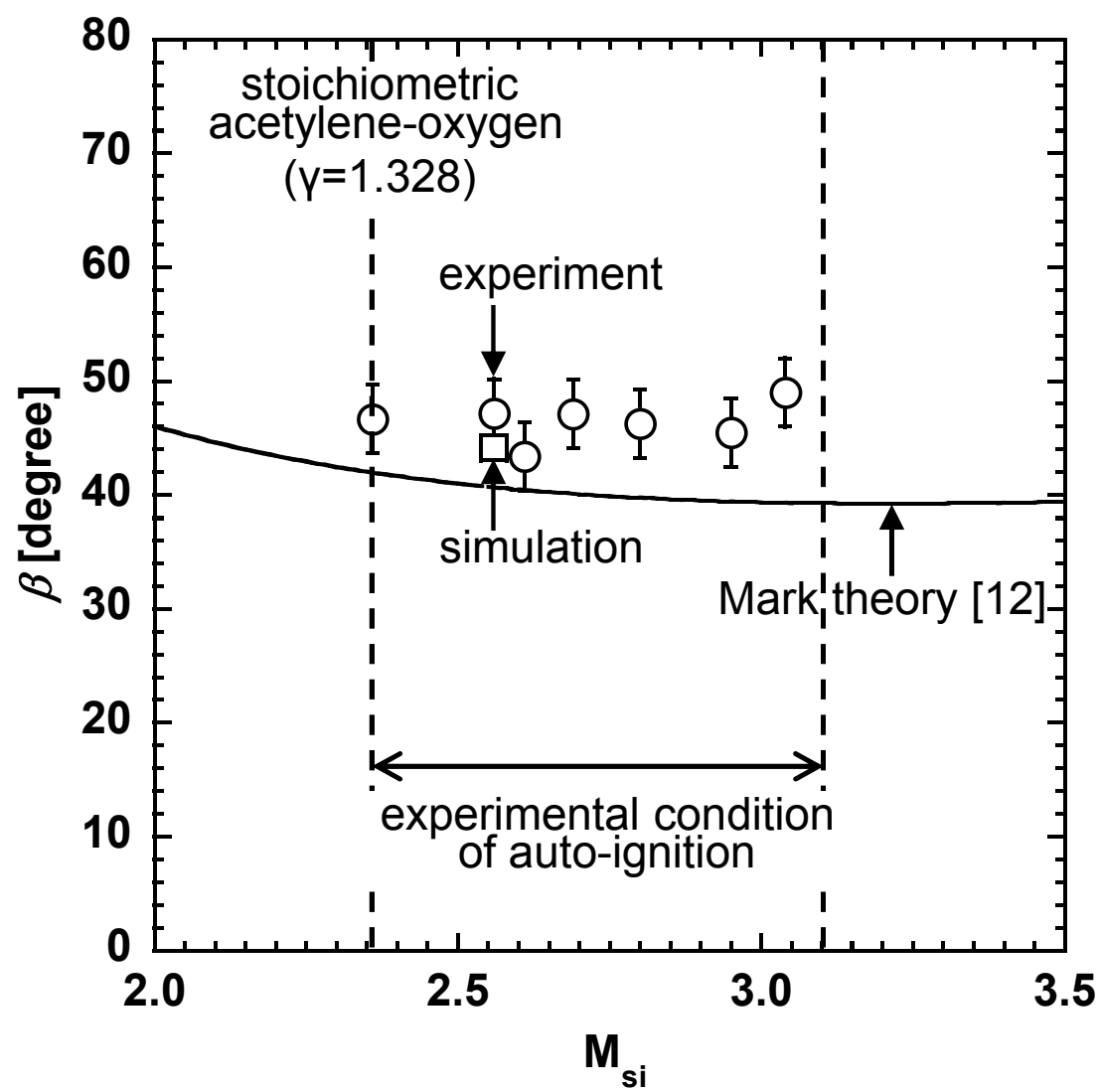

Fig. 16 Comparison of angle $\beta$ between Mark's theory [12] and our experimental value. The experimental plot is $\beta$ of shots $23,24,38,44,54,55$ and 58 . The symbol $\beta$ indicates the angle between the leading bifurcated shock waves and the top and bottom walls (refer to Fig. 8). The symbol $\mathrm{M}_{\mathrm{si}}$ is the Mach number of incident shock waves. 
Combustion and Flame 159 (2012) 2954-2966,

H. Yamashita, J. Kasahara, Y. Sugiyama, A. Matsuo



Fig.17 Distribution of local ignition positions with triple point trajectory of reflected shock waves. The triple point trajectories were scanned from Schlieren results of shot54. Plots show all ignition positions in the frame in which we observed the first ignition point. The $x-y$ coordinate is defined in Fig. 2 (2). 
Combustion and Flame 159 (2012) 2954-2966,

H. Yamashita, J. Kasahara, Y. Sugiyama, A. Matsuo

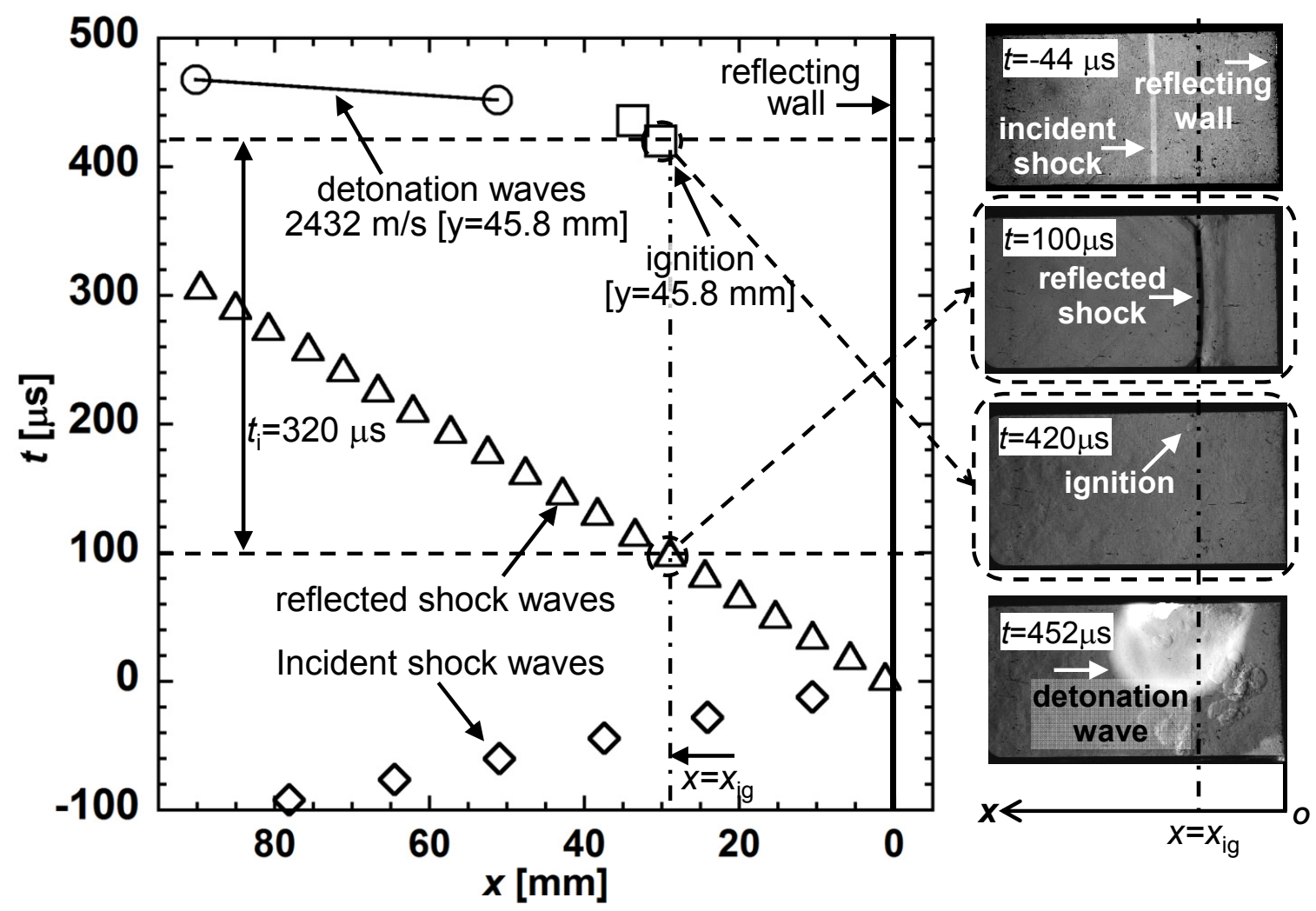

Fig. 18 Definition of induction time $t_{\mathrm{i}}$ on the $x$ - $t$ diagram in shot56. Experimental conditions are $\mathrm{M}_{\mathrm{si}}=2.58 \pm 0.02, p_{5 \mathrm{t}}=86 \pm 2 \mathrm{kPa}, T_{5 \mathrm{t}}=945 \pm 6 \mathrm{~K}$ and $t_{\mathrm{i}}=320 \mu \mathrm{s}$. The symbol $t$ is the time where the reflection time of incident shock is $t=0 \mu \mathrm{s}$. The $x-y$ coordinate is defined in Fig. 2 (2). 
Combustion and Flame 159 (2012) 2954-2966,

H. Yamashita, J. Kasahara, Y. Sugiyama, A. Matsuo



Fig. 19 Arrhenius plot. The solid line shows the regression curve which was determined by a leastsquares fit procedure. The dashed line shows the regression curve of Edwards et al. [39]. The activation energy of all experimental results was $E_{\mathrm{a}}=72 \pm 9 \mathrm{~kJ} / \mathrm{mol}$. Near-wall ignition and far-wall ignition are $E_{\text {an }}=74 \pm 5 \mathrm{~kJ} / \mathrm{mol}$ and $E_{\mathrm{af}}=71 \pm 13 \mathrm{~kJ} / \mathrm{mol}$, respectively. 
Combustion and Flame 159 (2012) 2954-2966,

H. Yamashita, J. Kasahara, Y. Sugiyama, A. Matsuo

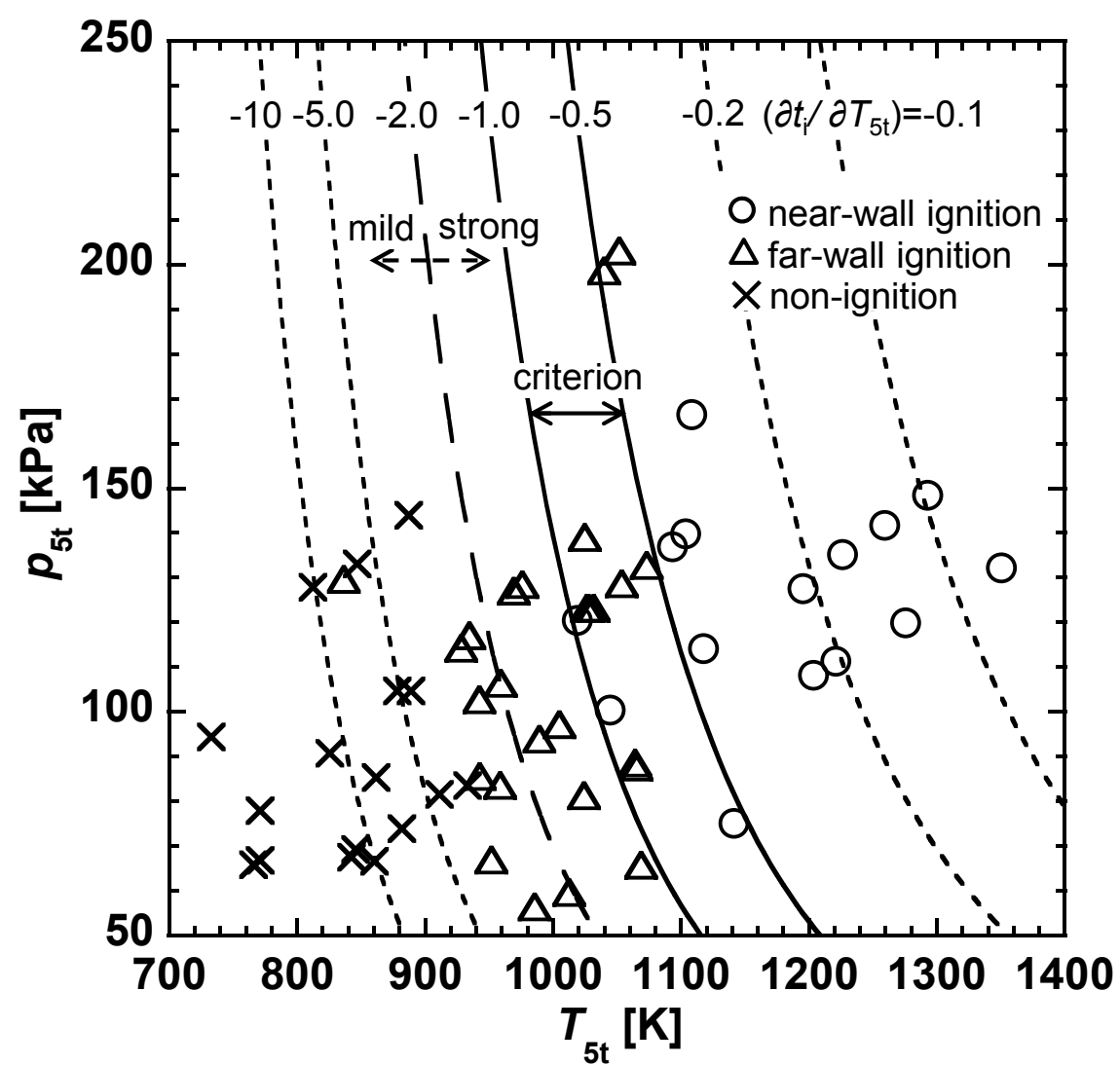

Fig. 20 Critical region between near-wall ignition and far-wall ignition on a $p_{5 \mathrm{t}}-T_{5 \mathrm{t}}$ diagram. The family of lines is calculated from equation (6). These lines are loci of constant gradients of induction time with respect to temperature at a constant pressure. The line of $\left(\partial t_{\mathrm{i}} / \partial T_{5 \mathrm{t}}\right)_{p \mathrm{t}}=-2.0$ shows the criterion distinguishing strong ignition from mild ignition estimated by Mayer and Oppenheim [18]. 
Combustion and Flame 159 (2012) 2954-2966,

H. Yamashita, J. Kasahara, Y. Sugiyama, A. Matsuo

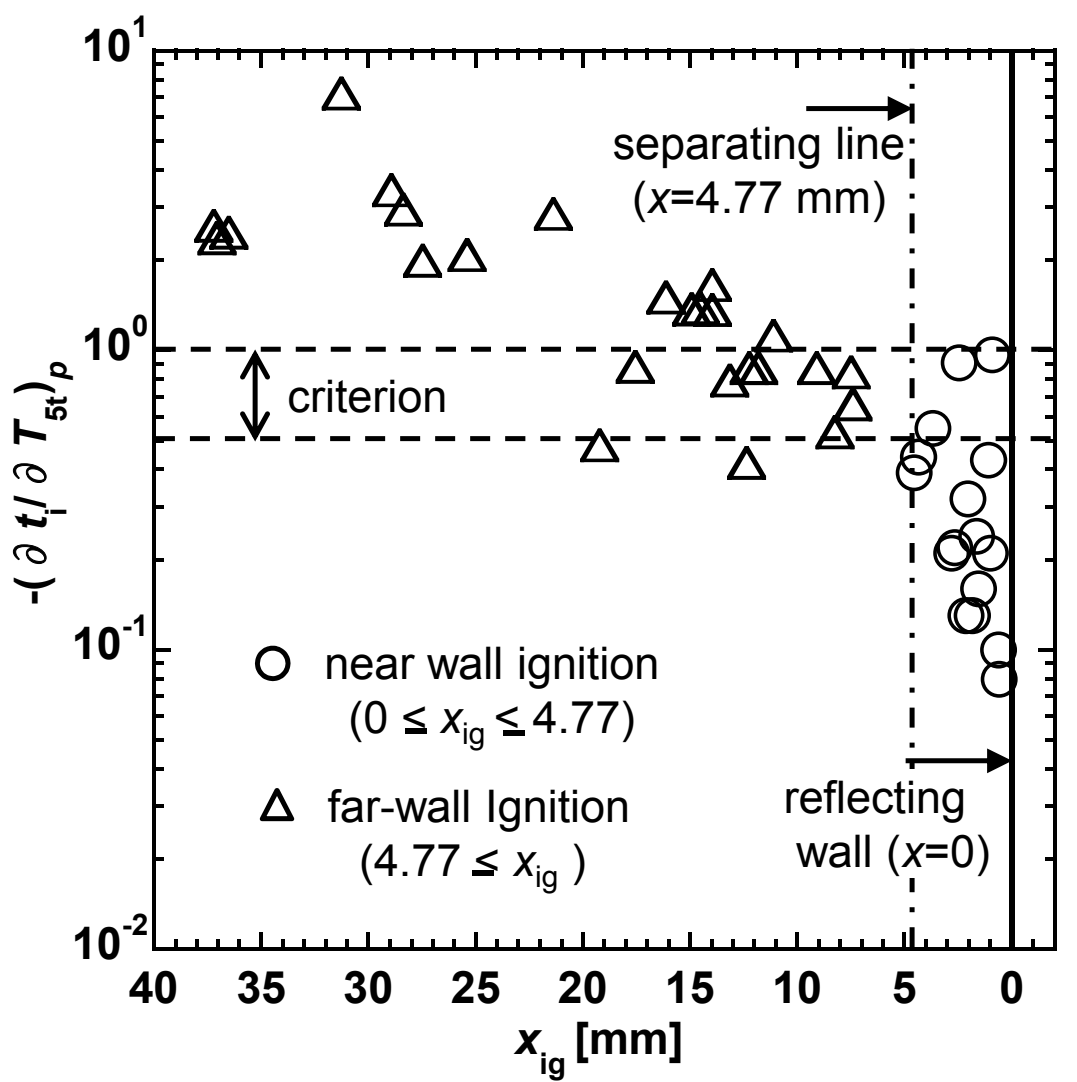

Fig. 21 Relation between $x_{\mathrm{ig}}$ and $\left(\partial t_{\mathrm{i}} / \partial T_{\mathrm{st}}\right)_{p 5 \mathrm{t}}$. The symbol $x_{\mathrm{ig}}$ indicates the ignition position defined in Fig. 14. The value of $\left(\partial t_{\mathrm{i}} / \partial T_{\mathrm{st}}\right)_{p \mathrm{t}}$ calculated from equation (6) indicates the sensitivity of induction time to non-uniformity of temperature distribution. 